\title{
The Bolund Experiment, Part II: Blind Comparison of Microscale Flow Models
}

\author{
A. Bechmann · N. N. Sørensen • J. Berg • J. Mann • \\ P.-E. Réthoré
}

Received: 12 November 2010 / Accepted: 6 July 2011 / Published online: 11 August 2011

(C) The Author(s) 2011. This article is published with open access at Springerlink.com

\begin{abstract}
Bolund measurements were used for a blind comparison of microscale flow models. Fifty-seven models ranging from numerical to physical were used, including large-eddy simulation (LES) models, Reynolds-averaged Navier-Stokes (RANS) models, and linearized models, in addition to wind-tunnel and water-channel experiments. Many assumptions of linearized models were violated when simulating the flow around Bolund. As expected, these models showed large errors. Expectations were higher for LES models. However, of the submitted LES results, all had difficulties in applying the specified boundary conditions and all had large speed-up errors. In contrast, the physical models both managed to apply undisturbed 'free wind' boundary conditions and achieve good speed-up results. The most successful models were RANS with two-equation closures. These models gave the lowest errors with respect to speed-up and turbulent kinetic energy (TKE) prediction.
\end{abstract}

Keywords Bolund - Blind comparison - Complex terrain - Computational fluid dynamics · Microscale · Validation

\section{Introduction}

The Bolund experiment performed in 2007 and 2008 provides verification data for atmospheric (microscale) models that resolve the flow on scales relevant for wind-turbine siting, i.e. typically down to metres. This report is the second of a two-part study on the Bolund experiment. In Part I, Berg et al. (2011) analyzed the measurements, while this part focuses on an intercomparison of microscale models.

The wind industry currently relies on a large variety of microscale models to assess wind resources in complex terrain. These models include guidelines, wind tunnels, and numerical methods such as linearized models and non-linear computational fluid dynamics (CFD).

\footnotetext{
A. Bechmann $(\varangle) \cdot$ N. N. Sørensen · J. Berg · J. Mann · P.-E. Réthoré The Wind Energy Department, Ris $\emptyset$ National Laboratory for Sustainable Energy/ Technical University of Denmark, 4000, Roskilde, Denmark e-mail: andh@risoe.dtu.dk
} 
There is, however, no consensus within the wind energy community on a standardized methodology for assessing resources in complex terrain. The difficulties in providing guidelines are twofold: experimental data available for validating the models are limited, and no systematic intercomparison of different models exists for flow in complex terrain: Through the Bolund experiment and Bolund blind comparison, both issues are addressed.

Jackson and Hunt (1975) presented their two-dimensional (2D) analysis of turbulent flow in complex terrain, which was later extended to three-dimensional (3D) flow by Mason and Stykes (1979). This theory has been refined and implemented numerically into commercial codes such as MS3DJH, MSFD and WAsP (Taylor et al. 1983; Walmsley et al. 1986; Beljaars et al. 1987; Troen and Petersen 1989). These so-called linear models have the advantage of producing computationally fast and accurate results for terrains of gentle slopes of less than 0.3 or $17^{\circ}$ (Wood 1995; Walmsley and Taylor 1996). Several measurement campaigns were conducted during the 1980 s to study the wind over low hills mainly in the framework of linear flow theory, e.g. Black Mountain (Bradley 1980), Blashaval Hill (Mason and King 1985), Askervein Hill (Taylor and Teunissen 1987), Kettles Hill (Salmon et al. 1988) and Hjardemål (Emeis et al. 1993). Among the experiments, the Askervein Hill project is the most widely known and best documented field campaign of the flow over low hills and represents a benchmark case for all microscale models. The field campaign was performed in 1982 and 1983 over the Askervein Hill (116 m high) located in the Outer Hebrides in Scotland with a steepness below $20^{\circ}$. The Askervein Hill is thus close to the limit of the linear models. Generally, linear models are able to quite satisfactorily reproduce the hilltop speed-up, but perform less successfully on the lee side.

Parallel to the development of linear models, numerical models based on non-linear equations have been applied. A 2D non-linear finite-difference model for the flow over low hills was developed by Taylor (1977). The development of numerical algorithms for solving Reynolds-averaged Navier-Stokes (RANS) equations was extensive in the 1970s and 1980s, and many studies have since been conducted with various turbulence closures. The classical two-equation $k-\varepsilon$ turbulence model originally formulated by Launder and Spalding (1974) and with various modifications for atmospheric flows (Panofsky and Dutton 1984; Detering and Etling 1985; Raithby et al. 1987; Zeman and Jensen 1987; Duynkerke 1987; Xu and Taylor 1997; Apsley and Castro 1997) appears to be a popular choice. Similar to the linear models, the Askervein Hill is a popular test case for RANS models (e.g. Castro et al. 2003; Raithby et al. 1987; Eidsvik 2005; Undheim et al. 2006). Compared with linear models, RANS models are able to capture the speed-up at the hilltop and provide slight improvements on the lee side.

Since the 1990s, large-eddy simulations (LES) have been applied to the atmospheric boundary layer over flat homogeneous terrain (e.g. Mason and Thomson 1992; Sullivan et al. 1994; Porté-Agel et al. 2000; Bechmann and Sørensen 2010b). One rationale behind using LES is that with increased computer power, a continuous refinement of computational resolution will eventually lead to solutions independent of the turbulence closure. While this may be correct, the terrain is covered by roughness elements that demand advanced wall models. These remain dependent on the chosen parametrization disregarding numerical resolution. LES of terrain flows are therefore faced with at least two problems: high computational cost and matching of the highly parametrized near-wall region with the well-resolved outer region. Despite the challenges of LES, its potential in modelling the flow over hills has long been recognized. Several authors have successfully simulated the wind over the Askervein Hill (Silva Lopes et al. 2007; Chow and Street 2009; Bechmann and Sørensen 2010b) and sinusoidal ridges (Brown et al. 2001; Wan et al. 2007); however, few studies in naturally complex terrain exist (Chow et al. 2006; Weigel et al. 2006; Bechmann and Sørensen 2010a). 
Many microscale models developed during the last 35 years have been validated with good results on low hills. However, well-documented experiments in complex terrain are necessary to completely verify their success. Jenkins et al. (1981) investigated the flow around Ailsa Craig, a 330-m-high island with slopes of approximately $30-45^{\circ}$. The measurements give a qualitative understanding of the flow nature, but are not ideal as a validation case for microscale models. Several wind-tunnel and water-channel studies have been conducted that include 2D ridges (Castro and Snyder 1982), a series of rough sinusoidal hills (Athanassiadou and Castro 2001), various generic terrains (Røkenes and Krogstad 2009) and a bell-shaped hill (Hunt and Snyder 1980). While these experiments are all excellent for testing microscale models, the wind energy community requires field experiments in complex terrain. The Bolund experiment meets this requirement (Berg et al. 2011).

Various model comparisons of atmospheric flows include linear models based on the theory of Jackson and Hunt (1975) and observations made at the Blashaval Hill (Mason and King 1985) by Walmsley et al. (1990). Comparisons of flow over a triangular ridge made by several two-equation RANS models were made by Kim and Patel (2000), and a comparison of four LES codes simulating the neutrally-stratified atmospheric boundary layer is found in Andren et al. (1994). Each study used identical parameters such as computational grids, boundary conditions and model constants in order to verify the modelling tools. A second method, blind comparison, was recently adopted by the National Renewable Energy Laboratory (NREL) (Simms et al. 2001). NREL performed tests of a wind turbine in the NREL/NASA-Ames wind tunnel and invited experts to predict the wind-turbine performance. The wind-tunnel data were not revealed prior to the blind comparison. This type of comparison can be used to identify uncertainties from both the model and the modeller.

Various microscale models are used daily by operators of different backgrounds in the wind-energy industry. Considering this fact, the goal of the Bolund blind comparison was to evaluate the accuracy of these models and the importance of user training and begin a process in the wind-energy community that could eventually lead to a standardized methodology for wind-resource assessment modelling. For objectivity, it was decided to maintain a blind comparison with anonymous results. Each participant was allowed to participate with several models and was further allowed to deliver several predictions from the same model if the methods used were distinctly different. The blind comparison therefore had to enable comparisons between the Bolund measurements and results from wind tunnels, water channels, CFD and a wide range of linearized flow models. The concept of the comparison was that the user himself would know how to most effectively set up and run his particular model to achieve the best possible results; these parameters could not be specified by the organisers. Therefore, each participant was required to operate his model to the best of his ability while following several basic guidelines comprising a general description of the simulation boundary conditions including 'free wind' and topography. In addition, the directive included 600 positions $(x, y, z)$ from which the model results were to be returned in a specific format. The participants were asked to follow the guidelines as closely as possible for their particular models, which allowed a model framework to be created for each different method. The only exceptions were the wind-tunnel and water-channel modellers, who were required to return results from only 130 points and simulate two of the four predefined cases. Each participant was asked to answer a set of questions about his particular simulation with one of several predefined answers. These answers, together with the simulation results, allowed the data to be sorted according to various parameters such as model type, user type, user experience, numerical approach and simulation time.

The blind comparison included 57 numerical and experimental results, which provided a unique insight into the accuracy of microscale models in 2010. This study draws the main 
conclusions of the blind comparison and provides instructions for modellers to recreate the four simulation cases and verify their microscale models. The paper contains three parts: a description of the experiment that supplies information for modelling of the Bolund Hill (Bechmann et al. 2009; Berg et al. 2011). The Bolund blind comparison is detailed next, including a description of the four simulation cases and the methodology for presenting results. Finally, the results are presented. In addition, we conclude with tabulated measurements and model predictions for one of the four simulation cases (Appendix, Tables A1, A2, and A2). These data allow readers to make their own model verifications and draw conclusions on model performance.

\section{The Bolund Experiment}

\subsection{Topography}

The Bolund experiment was performed during a 3-month period in 2007 and 2008 (Bechmann et al. 2009; Berg et al. 2011). From a modelling perspective, Bolund has many features that contribute to its suitability as a validation case for microscale models:

- The hill is surrounded by water with a long uniform fetch. The entire Bolund region therefore experiences the same equilibrium 'free wind' inflow for westerly winds, which can be specified as a model boundary condition. The validity of this assumption is investigated in Berg et al. (2011).

- The low height of Bolund $(h=12 \mathrm{~m})$ ensures that measurements are performed in the surface layer and that the flow can be modelled to be neutrally stratified. Although Bolund is relatively small, we expect the Reynolds number to be sufficiently large for the flow to have attained Reynolds-number independence (Berg et al. 2011).

- The ground of Bolund is uniformly covered by grass, and the flow is not influenced by individual roughness elements, which allows for rigorous description of ground boundary conditions.

Although these features make Bolund a well-defined validation case for microscale models, the geometric shape of the hill, a vertical escarpment with a $90^{\circ}$ crest, creates a challenging simulation case. As shown by Røkenes and Krogstad (2009), the crest geometry strongly affects flow separation. To unify the comparison, a roughness length of $z_{0}=0.015 \mathrm{~m}$ for Bolund and $z_{0}=0.0003 \mathrm{~m}$ for the surrounding water was dictated for the participants. The terrain to the east of Bolund, which is composed of farmland with low hills, was modelled using the land roughness length value for $x>327 \mathrm{~m}$.

\subsection{Coordinate System}

A right-handed regular east-north ( $x-y$ direction) coordinate system is used for the blind comparison, which differs from Berg et al. (2011) wherein the vertical axis ( $z$ direction) points upwards for positive values. The coordinate centre has been placed at the centre point (CP) of Bolund (694682.098; 6177441.825) (UTM WGS84 zone 32) to avoid rounding-off errors and make coordinates easier to interpret. The local height above ground level, $z_{\mathrm{agl}}$, is determined by $z_{\mathrm{agl}}=z-z_{\mathrm{gl}}$, where $z_{\mathrm{gl}}$ is the local terrain or water height. The water level fluctuated during the experiment; however, the water level for the official contour map of Bolund (Fig. 1) is set to $z_{\mathrm{gl}}=0.75 \mathrm{~m}$, that is, $z=0$ is $0.75 \mathrm{~m}$ below the water level. The origin of the wind direction is defined by $0^{\circ}$ true north and increasing clockwise, that is, $270^{\circ}$ denotes 


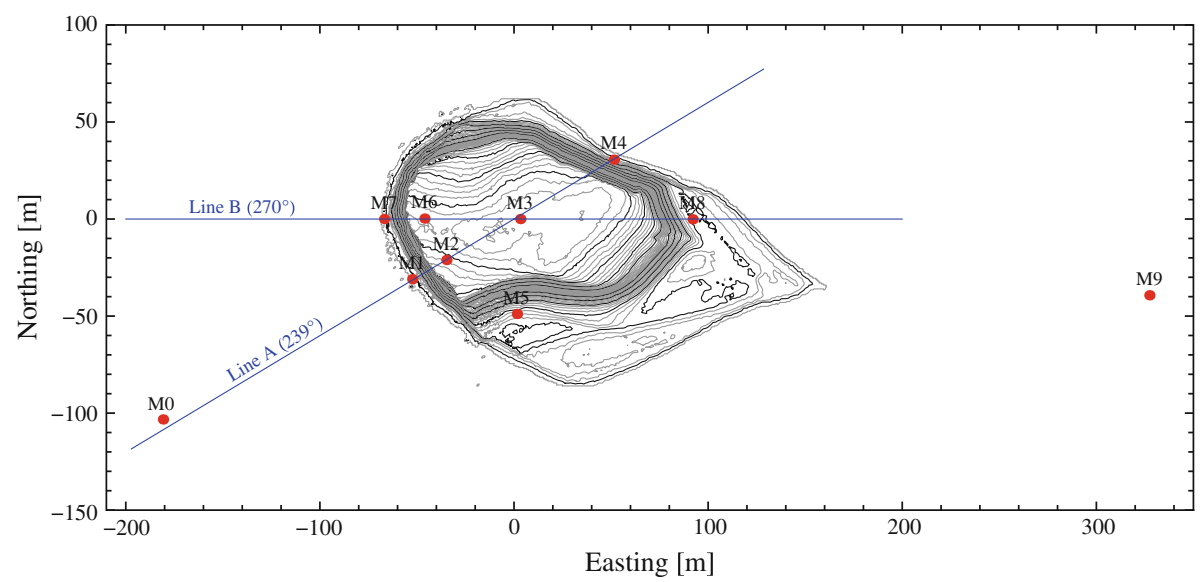

Fig. 1 Bolund contour map with $0.25 \mathrm{~m}$ contour interval. The mast positions (red dots) are located along two transects A and B. The map projection used for the coordinates is the universal transverse mercator (UTM) projection using the 6-degree longitudinal zone number 32 (UTM WGS84 zone 32). The centre point of the hill is $(694682.098 ; 6177441.825)$, which has been subtracted from all coordinate values in the remainder of the paper to avoid rounding-off errors and make the coordinates easier to interpret

Table 1 Horizontal distance in metres between the centre point $(\mathrm{CP})$ and masts projected onto the direction of the transects

\begin{tabular}{llllll}
\hline Line A & $-208.2(\mathrm{M} 0)$ & $-60.9(\mathrm{M} 1)$ & $-40.7(\mathrm{M} 2)$ & $2.8(\mathrm{M} 3)$ & $59.9(\mathrm{M} 4)$ \\
Line B & $-180.8(\mathrm{M} 0)$ & $-66.9(\mathrm{M} 7)$ & $-46.1(\mathrm{M} 6)$ & $3.2(\mathrm{M} 3)$ & $92.0(\mathrm{M} 8)$ \\
\hline
\end{tabular}

westerlies. In the selected coordinate system, the velocity vector is $\mathbf{u}=(u, v, w)$. If the wind originates from the east $\left(90^{\circ}\right)$, the $u$-component of the velocity will bear a negative sign.

\subsection{Instrumentation}

The instrumentation used in connection with the experiment was deployed on masts located along two transects through the hill's CP. The two transects, designated line A (239 direction) and line B (270 direction), are shown in Fig. 1. The undisturbed wind conditions measured at mast M0 and M9 for westerlies and easterlies are used as references and provide boundary conditions for simulations. Table 1 gives horizontal distances from several relevant measuring positions to $\mathrm{CP}$ projected onto the direction of transects $\mathrm{A}$ and $\mathrm{B}$. It should be noted that the positions of M3 and CP do not coincide. Table A2 (see Appendix) gives the positions of the individual cups (C) and sonics (S) with instrumentation ID defined by mast_number, approximate_height and instrument_type. For example, M0Z05S is the sonic placed at M0 at approximately $5 \mathrm{~m}$ above the ground.

\subsection{Ensemble-Averaged Statistics}

A thorough description of the methodology in which measurements were corrected, processed and stored can be found in Bechmann et al. (2009). The ensemble-averaged statistics used for the blind comparison were calculated by the following process: 
If $u_{i}^{n}$ denotes the $n$th sample of the velocity vector $u_{i}(i=1,2$ and 3 ) recorded by a sonic (sampling rate is $20 \mathrm{~Hz}$ ) and $N$ is the number of samples within a 10 -min time series, then the 10 -min mean, $\bar{u}_{i}$, is given by

$$
\bar{u}_{i}=(\bar{u}, \bar{v}, \bar{w})=\frac{1}{N} \sum_{n=1}^{N} u_{i}^{n} .
$$

Similarly, the mean variances and covariances can be calculated by

$$
\overline{u_{i}^{\prime} u_{j}^{\prime}}=\frac{1}{N} \sum_{n=1}^{N}\left[u_{i}^{n}-\bar{u}_{i}\right]\left[u_{j}^{n}-\bar{u}_{j}\right]
$$

from which the friction velocity, $u_{\star}=\left[\left|\overline{u^{\prime} w^{\prime}}\right|+\left|\overline{v^{\prime} w^{\prime}}\right|\right]^{1 / 2}$ and the turbulent kinetic energy (TKE), $\bar{k}=\left[\overline{\mid u^{\prime} u^{\prime}}|+| \overline{v^{\prime} v^{\prime}}|+| \overline{w^{\prime} w^{\prime}} \mid\right]^{1 / 2} / 2$, can be calculated. It should be noted that Berg et al. (2011) define the friction velocity in a different manner. The wind speed, $\bar{s}$, can be found by vector or scalar averaging. Because vector scaling is comparable to most numerical methods, this following approach is used:

$$
\bar{s}=\left[\bar{u}^{2}+\bar{v}^{2}+\bar{w}^{2}\right]^{1 / 2} .
$$

Although the Bolund Hill is relatively small, we expect the drag exerted by the hill on the flow to be Reynolds number independent (Berg et al. 2011). Due to the limited height of Bolund and because only cases with high wind speed and neutral stability are selected $\left(\bar{s}>5 \mathrm{~m} \mathrm{~s}^{-1}\right.$ and $\left|L_{\mathrm{MO}}\right|>250 \mathrm{~m}$, see Sect. 3.2), we will treat the atmosphere as neutral. For a neutral atmosphere at sufficiently high Reynolds numbers, the surface-layer flow is inertiadominated, and traditional scaling implies that the velocity scales with the friction velocity. This is exploited for the blind comparison. Each of the 10-min averaged velocity vectors are made non-dimensional with the reference friction velocity, $u_{\star}$, of the particular time series, and the ensemble average of several 10-min means is determined. The lowercase 0 denotes the reference friction velocity evaluated at the upstream mast M0 or M9 for westerly and easterly winds, respectively, measured by sonic M0Z05S or M9Z05S. Measurements from cup anemometers are also made non-dimensional with the friction velocity measured by the two reference sonics. The ensemble-averaged non-dimensional velocity vector, $\left\langle\bar{u}_{i} / u_{\star 0}\right\rangle$, is given by

$$
\left\langle\frac{\bar{u}_{i}}{u_{\star 0}}\right\rangle=\frac{1}{M} \sum_{m=1}^{M} \frac{\bar{u}_{i}^{m}}{\bar{u}_{\star 0}^{m}}
$$

where $M$ is the number of 10-min time series, and angled brackets \langle\rangle denote an average of several time series. The ensemble-averaged non-dimensional variances and covariances are calculated by

$$
\left\langle\frac{\overline{u_{i}^{\prime} u_{j}^{\prime}}}{u_{\star 0}^{2}}\right\rangle=\frac{1}{M} \sum_{m=1}^{M} \frac{{\overline{u_{i}^{\prime} u_{j}^{\prime}}}^{m}}{u_{\star 0}^{m 2}}
$$

from which the non-dimensional friction velocity, $\left\langle u_{\star} / u_{\star 0}\right\rangle$, and TKE, $\left\langle\bar{k} / u_{\star 0}^{2}\right\rangle$, can be determined. The standard deviation of the non-dimensional velocity vector (Appendix, Table A2) is calculated by 
Table 2 Free-wind conditions for the four simulation cases

\begin{tabular}{lllll}
\hline Case & $\begin{array}{l}\text { Wind } \\
\text { direction }\left(^{\circ}\right)\end{array}$ & $\begin{array}{l}\text { Upstream roughness, } \\
z_{0}\left(10^{-3} \mathrm{~m}\right)\end{array}$ & $\left\langle\bar{k}_{0} / u_{\star 0}^{2}\right\rangle(-)$ & $u_{\star 0}\left(\mathrm{~m} \mathrm{~s}^{-1}\right)$ \\
\hline 1 & $270(268)$ & $0.3(0.6)$ & $5.8(5.4)$ & $0.40(0.47)$ \\
2 & $255(254)$ & $0.3(0.4)$ & $5.8(6.4)$ & $0.40(0.37)$ \\
3 & $239(242)$ & $0.3(0.3)$ & $5.8(6.4)$ & $0.40(0.36)$ \\
4 & $90(95)$ & $15.0(14.4)$ & $5.8(6.7)$ & $0.50(0.51)$ \\
\hline
\end{tabular}

The actual free-wind conditions measured at the reference location (MOZ05S or M9Z05S), which differs from the free wind dictated for the blind comparison participants are in parentheses. The surface roughness length of the measurements was determined by fitting a logarithmic profile to the wind speed measured by the reference sonic

$$
\operatorname{sdev}\left(\left\langle\frac{\bar{u}_{i}}{u_{\star 0}}\right\rangle\right)^{2}=\frac{1}{M} \sum_{m=1}^{M}\left(\frac{\bar{u}_{i}^{m}}{\bar{u}_{\star 0}^{m}}-\left\langle\frac{\bar{u}_{i}}{u_{\star 0}}\right\rangle\right)^{2} .
$$

\section{The Blind Comparison}

\subsection{Simulation Cases}

The blind comparison consisted of four predefined simulation cases (cases 1-4) identified by the directions of the undisturbed wind $\left(270,255,239\right.$ and $\left.90^{\circ}\right)$. The first three cases were chosen to accommodate the westerly wind directions originating from a fjord. The fourth case, $90^{\circ}$ originating from land, was included to add complexity. For each case, participants should apply specific free-wind conditions for their simulations. These conditions differed slightly from the measured free wind; however, this result was largely a deliberate choice. To appropriately compare microscale models, it is important to run all models with the same boundary conditions. By simplifying the free-wind conditions, user uncertainties regarding simulation setup could be minimized. An additional reason for the difference in free-wind conditions is that the measurement analysis was incomplete at the time the invitations for the blind comparison were issued.

The four simulation cases are defined in Table 2 by wind direction, roughness length and TKE of the simulated free wind. Participants were asked to apply the following well-known logarithmic velocity profile at their reference locations or model space boundaries if possible:

$$
\langle\bar{s}\rangle_{z_{\mathrm{agl}}}=\frac{u_{\star 0}}{\kappa} \log \left(\frac{z_{\mathrm{agl}}}{z_{0}}\right),
$$

where $\kappa=0.4$, and the roughness length, $z_{0}$, and friction velocity, $u_{\star 0}$, are given in Table 2 . Similarly, TKE (if available in the model) should be set constant to height by the following value:

$$
\left\langle\frac{\bar{k}}{u_{\star 0}^{2}}\right\rangle=5.8 .
$$

To unify comparisons, participants should use the same air properties if needed as input for the models. Simulations should be run in dry air with a density of $\rho=1.229 \mathrm{~kg} \mathrm{~m}^{-3}$ at sea level, dynamic viscosity of $\mu=1.73 \times 10^{-5} \mathrm{~kg} \mathrm{~m}^{-1} \mathrm{~s}^{-1}$ and temperature of $T=15^{\circ} \mathrm{C}$ (zero 

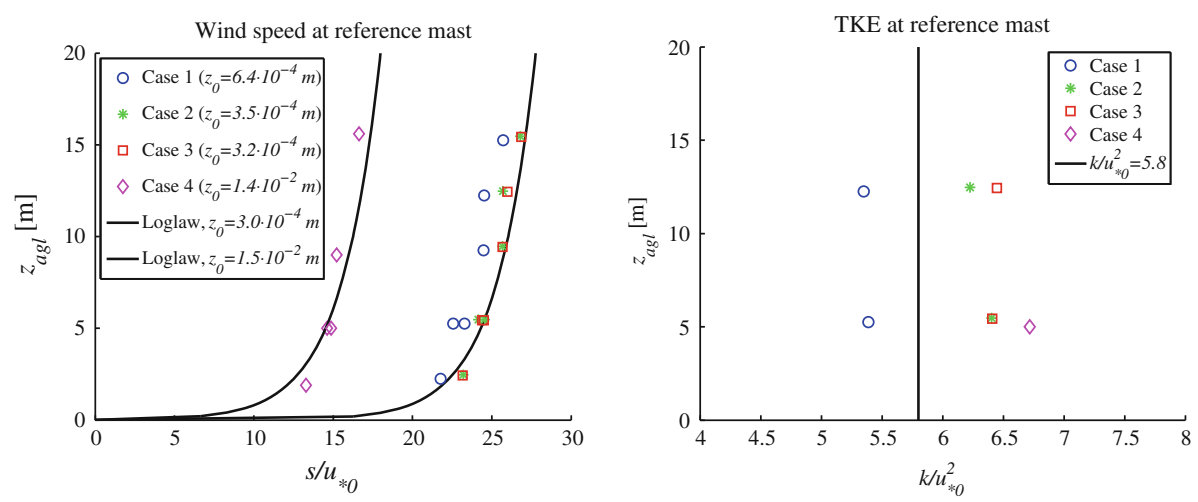

Fig. 2 Upstream profiles of wind speed and TKE for the four cases. Symbols represent measurements, and solid lines denote input specified to the participants. Although the measured upstream wind differed for cases 1-3 (indicated by different colours and symbols), the participants were asked to use identical upstream conditions for all cases

heat flux $\overline{w^{\prime} \theta^{\prime}}=0$ ). In addition, gravitational acceleration of $g=9.82 \mathrm{~m} \mathrm{~s}^{-1}$ and a Coriolis parameter of $f=10^{-4} \mathrm{~s}^{-1}$ should be used if needed.

Six hundred positions $(x, y, z)$ were given to each participant from which model results should be returned for each simulation case. These positions include the ten mast positions (Appendix, Table A2) and positions along transect A and B in 2 and $5 \mathrm{~m}$ above ground level.

\subsection{Free-Wind Conditions}

The measurements used for each simulation case were based on 10-min ensemble-averaged statistics as described in Sect. 2.4. The measurements were selected from the complete Bolund database derived from various criteria. The first criterion was based on the mean wind direction at the reference location, which should be within $\pm 8^{\circ}$ of that specified by the simulation case. Secondly, only neutrally stratified atmospheric conditions fulfilling $\left|L_{\mathrm{MO}}\right|>250 \mathrm{~m}$ and $5 \mathrm{~m} \mathrm{~s}^{-1}<\bar{s}_{0}<12 \mathrm{~m} \mathrm{~s}^{-1}$ at the reference location were used, where $L_{\mathrm{MO}}$ is the Obukhov length,

$$
L_{\mathrm{MO}}=-\frac{u_{\star 0}^{3} \bar{\theta}}{g \kappa \overline{w^{\prime} \theta^{\prime}}},
$$

and $\theta$ is the potential temperature. Finally, because the water level fluctuated during the experiment, the measurement choices were also based on the water level. To remove the outliers, data only with water levels of $0.75 \pm 0.40 \mathrm{~m}$ were used. The only exception was for simulation case 4 in which few available time series constituted relaxed restrictions on the water level. For case 4 , data with water levels from -0.5 to $1.15 \mathrm{~m}$ were used. We expect the water level to have a smaller effect on the Bolund winds for eastern wind directions.

The ensemble-averaged mean wind and standard deviations for simulation case 3 are listed in the Appendix, and the free-wind profiles of velocity and TKE are shown in Fig. 2. Differences are evident between the measured free-wind conditions and those specified for the blind comparison participants (Table 2). An explanation for the deviations between measurements and the logarithmic velocity profile can be found in Berg et al. (2011). 
During the experiment, several anemometers were added and several of the sonics were moved to new locations. These instruments can be identified by their lower numbers of time series included in the ensemble averages (Appendix, Table A2).

\subsection{Presentation of Results}

Although free-wind conditions were specified for the participants, differences exist. Therefore, several of the 600 result positions were located at reference mast positions (M0 and M9), which allowed for results to be presented in a dimensionless form. Because not all models are capable of predicting friction velocity, all results are made dimensionless with a reference velocity such as

$$
\Delta S_{\mathrm{s}}=\frac{\langle\bar{s}\rangle_{z_{\mathrm{agl}}}-\left\langle\bar{s}_{0}\right\rangle_{z_{\mathrm{agl}}}}{\left\langle\bar{s}_{0}\right\rangle_{z_{\mathrm{agl}}}}
$$

where $\Delta S_{\mathrm{S}}$ is the simulated fractional speed-up and $\langle\bar{s}\rangle_{0}$ is the simulated wind speed at the reference mast location. Because modellers returned predictions at specified heights above ground level, calculating speed-up for the models is simple. For the measurements, however, the various instruments were not precisely located at the same height above the ground. In cases $1-3$, for example, MOZ05S is located at $z_{\mathrm{agl}}^{*}=5.2-5.5 \mathrm{~m}$ (because of water-level changes), and $M 3 Z 05 S$ is located at $z_{\mathrm{agl}}=5.0 \mathrm{~m}$. To obtain a reference velocity at a specific height for the measurements (in this example, $z_{\mathrm{agl}}=5.0 \mathrm{~m}$ ), a logarithmic profile is fitted to the wind speed measured by the reference sonic (MOZO5S), and a corrected reference wind speed can be calculated:

$$
\left\langle\frac{\bar{s}_{0}}{u_{\star 0}}\right\rangle_{z_{\mathrm{agl}}}=\left\langle\frac{\bar{s}_{0}}{u_{\star 0}}\right\rangle_{z_{\mathrm{agl}}^{*}}+\frac{1}{\kappa} \ln \left[\frac{z_{\mathrm{agl}}}{z_{\mathrm{agl}}^{*}}\right]
$$

where $z_{\mathrm{agl}}^{*}$ is the actual height of the reference sonic and $\left\langle\bar{s}_{0} / u_{\star}\right\rangle_{z_{\mathrm{agl}}^{*}}$ is the non-dimensional wind speed measured by the reference sonic. Having determined the non-dimensional reference wind speed at the desired height, the measured speed-up is calculated by

$$
\Delta S_{\mathrm{m}}=\frac{\left\langle\bar{s} / u_{\star 0}\right\rangle_{z_{\mathrm{agl}}}-\left\langle\bar{s}_{0} / u_{\star 0}\right\rangle_{z_{\mathrm{agl}}}}{\left\langle\bar{s}_{0} / u_{\star 0}\right\rangle_{z_{\mathrm{agl}}}}
$$

where $\left\langle\bar{s} / u_{\star 0}\right\rangle_{z_{\mathrm{agl}}}$ and $\left\langle\bar{s}_{0} / u_{\star 0}\right\rangle_{z_{\mathrm{agl}}}$ are now evaluated at the same height. It should be noted that only the measured reference wind is corrected. Simulation results should be made non-dimensional with the simulated reference wind and measurements with the (corrected) measured reference wind.

TKE can also be normalized with the reference wind speed $\left\langle\bar{k} / \bar{s}_{0}^{2}\right\rangle$, where $\bar{k}$ is the local value divided by the velocity at the reference location. For comparison between simulations and measurements, the TKE increase is defined as

$$
\begin{aligned}
\Delta k_{\mathrm{s}} & =\left\langle\bar{k} / \bar{s}_{0}^{2}\right\rangle-\left\langle\overline{k_{0}} / \bar{s}_{0}^{2}\right\rangle, \\
\Delta k_{\mathrm{m}} & =\frac{\left\langle\bar{k} / u_{\star 0}^{2}\right\rangle_{z_{\mathrm{agl}}}}{\left\langle\overline{s_{0}} / u_{\star 0}\right\rangle_{z_{\mathrm{ag} 1}}^{2}}-\frac{\left\langle\overline{k_{0}} / u_{\star 0}^{2}\right\rangle_{z_{\mathrm{ag}}^{*}}}{\left\langle\overline{s_{0}} / u_{\star 0}\right\rangle_{z_{\mathrm{agl}}}^{2}},
\end{aligned}
$$

where subscript 0 denotes the reference TKE. The measured reference TKE is determined by the reference sonic and is not corrected for height; it is considered constant with height. The reason for comparing the TKE increase instead of actual TKE is to include models that 
did not exactly fulfil the specified free-wind conditions. For example, only a few of the LES models were able to achieve the specified free-wind conditions, and consequently, had inaccurate TKE predictions. However, the potential of the LES models can be investigated by subtracting TKE of the free wind and instead comparing the models' abilities to predict the increase of TKE.

\section{Results}

\subsection{Participants}

The 57 submitted model runs of the Bolund blind comparison are listed in Table A1 (see Appendix). Because the results are anonymous, they are listed with an identity number known only to each individual participant. Approximately $40 \%$ of the submitted results were by the wind-energy industry, including energy companies, consultancies and wind-turbine manufacturers; $35 \%$ came from research centres and universities; and approximately $25 \%$ of the results were submitted by companies that develop and sell CFD software.

The information given (Appendix, Table A1) is obtained from a questionnaire answered by all participants. The table shows that of the 57 models participating in the comparison, 25 of the modellers considered themselves model developers, 28 of them model users, and four participants gave no answer. The results are divided into three types: experimental (two results), non-linear CFD (40 results) and linearized model (11 results). Four models remain undefined. Initially, the number of participating CFD models appeared high compared to that of linearized models: 40 compared to 11 . In the wind-turbine industry, linearized models are widely used. However, these types of models are not designed for very steep terrain; this limitation may have affected the number of submissions. The large number of CFD results submitted signifies that CFD methods have been embraced by the wind-energy industry and are being used to analyze complex terrain. The two experimental results submitted consist of wind-tunnel and water-channel measurements. Although these methods are widely used in the aerospace industry and by city planners, they have not been adopted to the same degree for wind-turbine site assessment. Many questionnaire items were designed for numerical models and are not useful for the two experimental approaches.

Column 4 of Table A1 details the methods employed. The CFD models can be subdivided into groups that use one-equation RANS (six results), two-equation RANS (27 results) and LES (six results). By querying the participants and evaluating method descriptions, it is evident that the CFD method used most often was the RANS approach with the two-equation $k-\varepsilon$ turbulence model (Launder and Spalding 1974; Raithby et al. 1987). Twenty-four $k-\varepsilon$ results were submitted, and no other method, numerical or experimental, approached this number. Different variants of the $k-\varepsilon$ method were included; however, the $k-\varepsilon$ RANS method remains the most popular CFD approach used by the wind-energy industry. Only six results characterized as LES were submitted for the blind comparison. This result is both surprising and disappointing as LES is expected by many to succeed RANS. Through evaluation of the number of computational grid points used for the simulations (column 5), it was determined that LES simulations use an average of 2.1 million grid points, whereas CFD simulations use 3.8 million grid points. The average results of RANS therefore appear to be better resolved than those of LES. This finding is peculiar because the LES approach depends on resolving most of the turbulence, whereas the RANS method models the turbulence. Method descriptions given by many participants reveal that many of the LES approaches apparently should have been characterized as zonal LES. The participants were not offered this option in the 

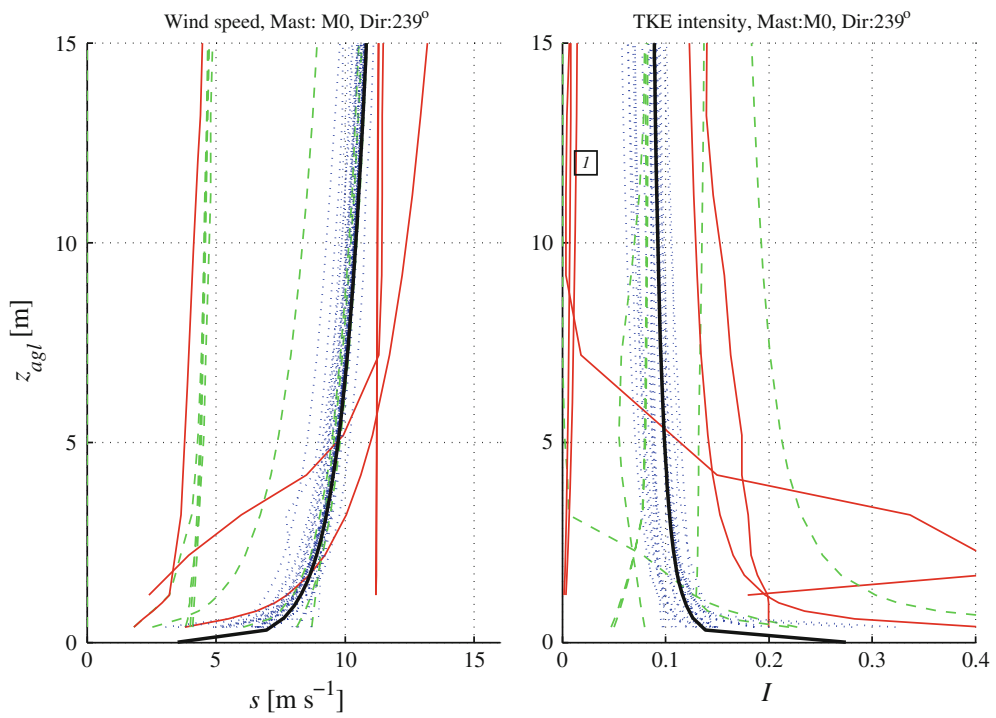

Fig. 3 Left: dimensional free-wind speeds for the simulations at M0 for case 3. The blue dotted lines indicate simulations in close agreement to the specified free wind, represented by the thick black line. The green dashed lines indicate simulations using different free-wind conditions, and the red thin solid lines indicate the free winds for the LES simulations. Right profiles of turbulence intensity at M0 for the simulations. Three lines indicated with a ' 1 ' represent LES simulations with laminar inflow

questionnaire. Zonal LES describes a method that is mostly RANS but switches to LES in flow regions dominated by inherent large-scale unsteadiness. The 11 linearized results are more difficult to subdivide. When queried on the turbulence model used, participants answered 'no model' or chose not to answer. Therefore, the predefined answers may have been inappropriate.

The final two columns of Table A1 give information on the computational efforts utilized by the participants. Column 6 shows the computational time (in minutes, obtained by a wall clock) spent for all four flow cases, and column 7 gives the number of CPUs used to perform these computations. It is evident that the computational time spans from $6 \mathrm{~s}$ to 44 days. Readers who attempt to analyze these times should be aware that many of the computations are iteratively solved whereby the user himself chooses the level of convergence. This convergence level is very different for many of the models and has a major influence on the computational time. Although computational time is an important parameter for commercial models, it has not been the focus of the blind comparison. It should also be noted that many of the processes involved in wind-tunnel measurements can be automated, and the time required to perform the experiments can be comparable to many CFD computations.

\subsection{Reference Wind}

Before the dimensionless results are compared, we discuss the free-wind conditions used in the simulations. A thorough analysis of the measured free winds can be found in Berg et al. (2011).

Figure 3 shows all simulated profiles of velocity and turbulence intensity (see Eq. 16 and subsequent definition) for case $3\left(239^{\circ}\right.$ direction) at the reference location M0. 
The figure also shows the free-wind conditions specified by the organisers (thick black lines). The simulations have been divided into two groups: those in close agreement with the specified reference wind are indicated by blue dotted lines, and those not in close agreement are indicated by green dashed lines. The criteria were $\mp 15 \%$ on the wind speed and $\mp 30 \%$ on TKE intensity. The LES simulations are shown as red solid lines in the figure. Generally, many participants were able to specify their free-wind conditions in agreement with the specified conditions. Thirty-nine of 51 simulations within the same criteria fulfilled the freewind boundary conditions for this simulation case. Several simulations that failed to fulfil the specified conditions had accurately applied the specified turbulence intensity but used an insufficiently low free-stream wind speed. The dimensionless results from these simulations may very well be comparable to the other simulations through an independence of Reynolds numbers.

Of the five LES simulations that have simulated flow case 3, none managed to achieve the specified free-wind boundary conditions. Three of the LES simulations (ID0041, ID0042, ID0043) clearly used laminar inflow conditions, that is, a constant velocity profile with no resolved turbulence. These simulations have been marked with a ' 1 ' on the figure. The final two LES simulations (ID0003, ID0046) were turbulent, but their turbulence intensities were overly high. Only a few LES modellers were able to deliver results for the blind comparison, and even fewer managed to generate the specified free-wind boundary conditions. This result shows that it is not trivial to perform large-eddy simulations of flow over complex terrain and that the free-wind boundary conditions are difficult to control. The physical models, water channel and wind tunnel, in contrast to the LES models, were able to generate the specified conditions of wind speed and turbulence intensity very closely.

\subsection{Speed-up}

In this section, the measured and simulated speed-up are compared by investigating the speedup along transect $\mathrm{A}$ for flow along the same direction (simulation case 3 ). This direction was selected since it is the best instrumented direction. To ease the presentation of the large amount of data, the simulations have been divided into five groups: experimental methods, RANS models with one- or two-equation turbulence models, linearized models and LES models.

Figure 4 shows the measured and simulated speed-up at 2 and $5 \mathrm{~m}$ above ground level. The numerical models are shown as coloured lines, and the experimental method as small black symbols. The Bolund measurements are presented as large circles and squares representing sonics and cup measurements, respectively; this coding is used throughout. The speed-up was set to zero at M0, approximately $150 \mathrm{~m}$ from the Bolund escarpment. At that distance, the flow was expected to be unaffected by the hill; however, the simulations predicted an average $0.5 \%$ decrease in the wind speed. All models were able to capture the speed-down in front of the escarpment (M1) and on the escarpment edge (M2) at $5 \mathrm{~m}$ above ground level. At the centre of Bolund at M3, the linearized models began to overestimate the speed-up and clearly predicted an overly high wind speed on the lee side. All experimental methods and RANS models were able to capture the gross features of the speed-up, with the RANS two-equation models showing the best performance. At $2 \mathrm{~m}$ above ground level, the scatter of the simulations increased. The models continued to capture the low wind speed in front of the hill; however, they were inefficient in capturing the speed-up at the escarpment edge (M2). At this position and at the centre of the hill, the LES models scored high, slightly outperforming the RANS models and the experimental methods. The linearized models appeared to perform better on the lee side; however, this result may not be a representative function (see Fig. 6). 


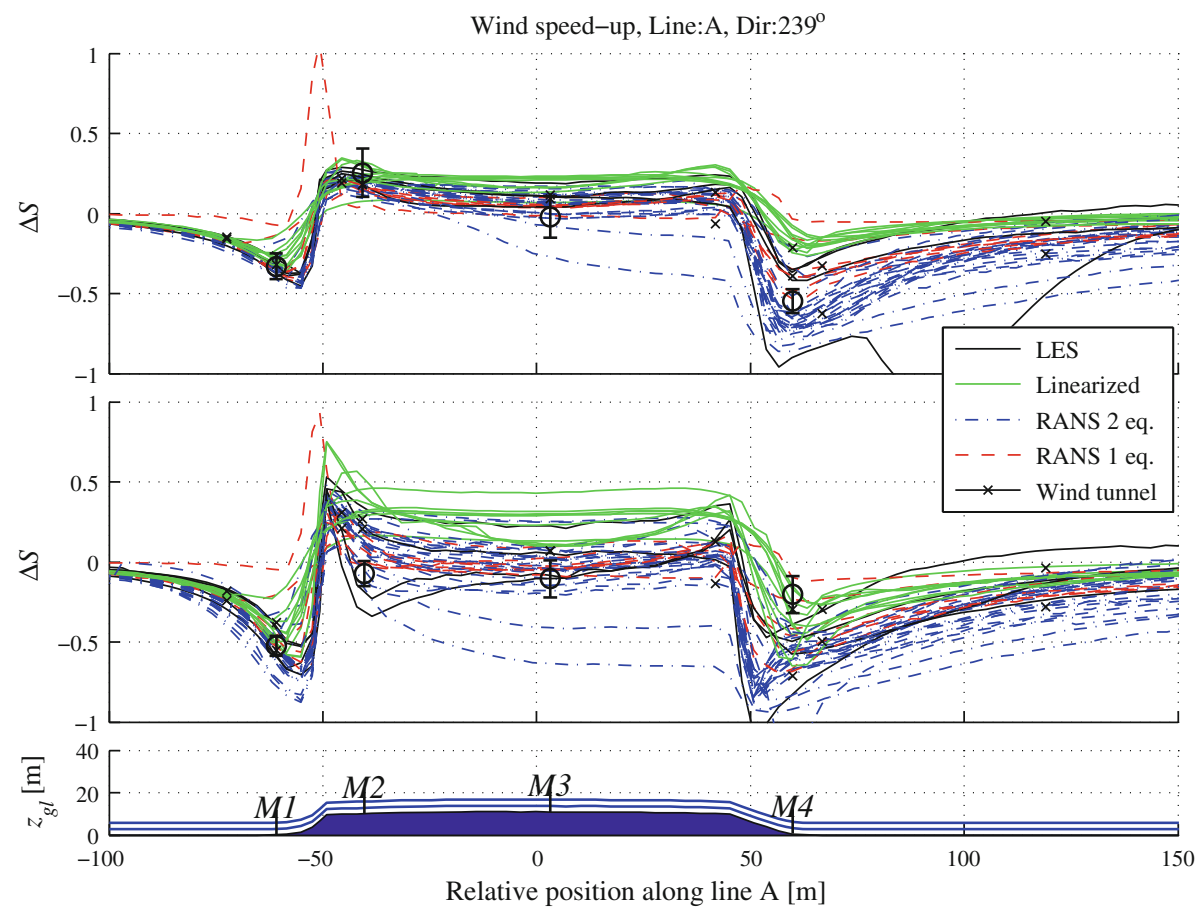

Fig. 4 Measured and simulated speed-up along line A for simulation case 3 as a function of relative position (see Table 1). Top $z_{\mathrm{agl}}=5 \mathrm{~m}$, bottom $z_{\mathrm{agl}}=2 \mathrm{~m}$. See the text for explanation of symbols

One could argue that the scatter of the simulation results is significant. In several regions of the hill, speed-up estimations range between 0 and -1 . One should, however, remember that the simulation results are obtained from a large range of completely different microscale models. In addition, simulations were performed blindly, and modellers were not allowed to correct their submitted results. If a few outliers are removed, the scatter within each model type is greatly reduced. In this case, consistent and reproducible results from any of the five model types appear possible to obtain. When comparing with measurements, one should remember that inaccuracies in anemometer position affect the speed-up plots. In Fig. 4, the measurements at M4 are plotted as if they were made at $z_{\mathrm{agl}}=2 \mathrm{~m}$ and $z_{\mathrm{agl}}=5 \mathrm{~m}$. As seen in Table A2 (see Appendix), this result differs greatly from the case for this mast $\left(z_{\mathrm{agl}} \approx 1.4 \mathrm{~m}\right.$ and $z_{\mathrm{agl}} \approx 4.4 \mathrm{~m}$ ). When examining speed-up profiles (below), the individual anemometers on a particular mast may not be located at the exact horizontal position, and inaccurate mast positioning is also a possibility. Such measuring inaccuracies can cause the simulation results in the figures to appear worse or, perhaps, better.

Speed-up profiles at masts M1, M2, M3 and M4 are shown in Figs. 5 and 6. Again, it is evident that all models, with a few exceptions, were able to capture the speed-down at M1. At the escarpment edge (M2), all models captured the speed-up above $z_{\mathrm{agl}}=5 \mathrm{~m}$. Below this height, the linearized models inaccurately predicted the speed-up, whereas the two-equation models and the LES models more accurately captured the low wind speeds measured near the ground. As described by Berg et al. (2011), mast M2 was positioned on the edge of a small zone of detached flow with intermittent negative wind velocity. The description for this gusty flow can only be accurately categorized by models able to resolve turbulence. 


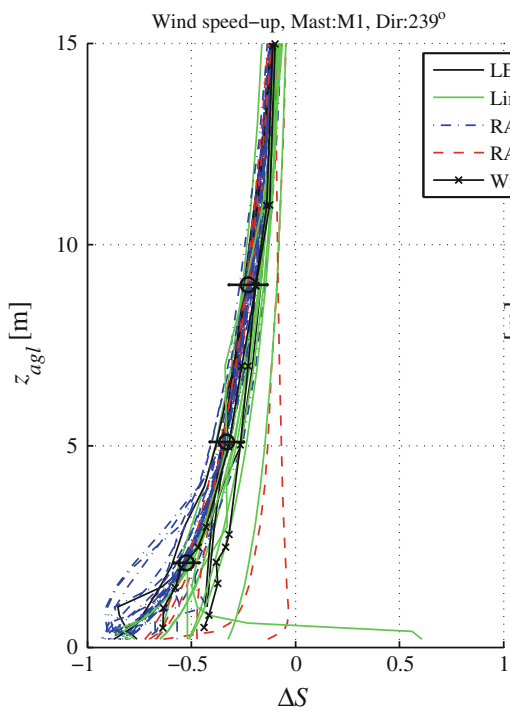

Wind speed-up, Mast:M2, Dir: $239^{\circ}$
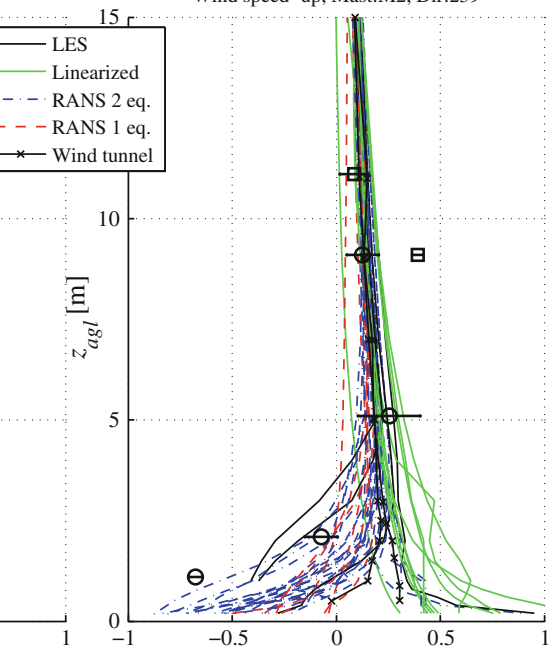

$\Delta S$

Fig. 5 Left: simulated and measured speed-up profiles at M1. Right: speed-up profiles at M2

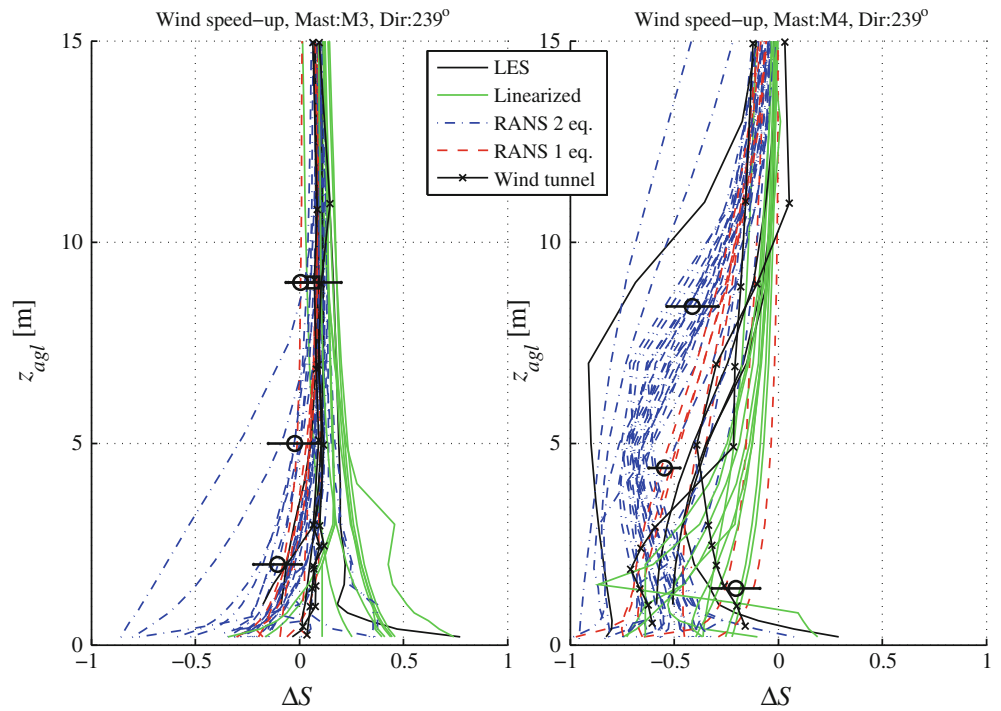

Fig. 6 Left: simulated and measured speed-up profiles at M3. Right: speed-up profiles at M4

The cup measurements at $z_{\mathrm{agl}}=9 \mathrm{~m}$ appeared unreliable in this case. As seen in Table A2, the statistics from this cup are based on only two 10-min time series. At M3 and M4, the RANS models appear to have the most accurate speed-up predictions with the experimental methods showing reasonable results.

To quantify the errors of the simulated speed-up, we define the error by

$$
R_{\mathrm{S}}=100\left(\Delta S_{\mathrm{S}}-\Delta S_{\mathrm{m}}\right)
$$


Table 3 Mean absolute speed-up error (see Eq. 15) for each model type for all sonics in all four simulation cases and for cases 1 and 3

The numbers in parentheses signify the error for the highest performing model of the particular model type

\begin{tabular}{lll}
\hline & All cases & Case 1+3 \\
\hline RANS 2 eq. & $13.6(10.2)$ & $15.1(11.4)$ \\
Experiment & - & $14.7(13.3)$ \\
RANS 1 eq. & $16.3(12.2)$ & $17.2(13.8)$ \\
LES & $16.0(13.5)$ & $17.3(14.1)$ \\
Linearized & $21.0(18.5)$ & $23.7(20.6)$ \\
All models & 15.8 & 17.3 \\
\hline
\end{tabular}

where superscript $\mathrm{s}$ and $\mathrm{m}$ denote the simulated and measured speed-up, respectively. By using this definition instead of a traditional percentage error, large near-ground errors (where $\bar{s} \approx 0$ ) that could corrupt mean error calculations are avoided.

Table 3 shows the mean absolute speed-up error for all simulation cases and cases 1 and 3 in which the mean absolute error for the experimental methods was based on fewer positions. All simulation results used in the error calculations (see Appendix, Table A2) were obtained at the exact height as that of the sonics given in the Appendix, Table A2. In Table 3, the error for the best performing model for each model type is given in parentheses. This number shows the actual performance potential of a particular model type, while the averaged error includes the effect not related to particular models such as various user errors.

Table 3 shows that the mean error for all models is $17.3 \%$. The ranking for model type is $11.4 \%$ for RANS two-equation, $13.3 \%$ for experimental methods, $13.8 \%$ for RANS oneequation, $14.1 \%$ for LES and $20.6 \%$ for the linearized models. The linearized results were expected because these models were not designed for the steep terrain of Bolund. The experimental methods ranked second, closely followed by RANS one-equation and LES, while the RANS two-equation method scored the highest with an error of $11.4 \%$.

The presented mean errors are larger than would be accepted by any wind-farm developer. Such large errors are caused by the steepness of Bolund, which violates assumptions of the linearized models, and the location of the measuring equipment, which was close to the ground These effects can be illustrated by calculating the mean errors for positions at $z_{\mathrm{agl}}<5 \mathrm{~m}$ and $z_{\mathrm{agl}} \geq 5 \mathrm{~m}$. Doing this, it was determined that the error for the highest performing model is $17.1 \%$ for the positions below $5 \mathrm{~m}$ and $6.5 \%$ for those above $5 \mathrm{~m}$. Many modellers consider the flow over low hills to be divided into two layers: an inner layer near the ground dominated by turbulent stresses and an outer layer above the ground considered inviscid. Many methods exist for estimating this inner-length scale (Jackson and Hunt 1975; Jensen et al. 1984). Bolund Hill was roughly estimated to have $l_{i}=2 \mathrm{~m}$ (Berg et al. 2011), which is the apparent height below which simulation accuracy drops. This effect is verified in Fig. 4, which shows the scatter on the speedup predictions to be much larger at $z_{\mathrm{agl}}=2 \mathrm{~m}$, the inner layer, than at $z_{\mathrm{agl}}=5 \mathrm{~m}$, the outer layer. For large hills, the inner layer can reach the hub height of modern windturbines. Therefore, inaccurate resource predictions can be expected for very complex wind-turbine sites if simulation results are not validated or corrected against on-site measurements.

Figure 7 shows wind deflection in degrees, with zero along the 239 direction at $2 \mathrm{~m}$ and $5 \mathrm{~m}$ above ground level. The RANS two-equation models perform the best, and together with several LES and experimental methods, are the only models that can capture the large measured shift at M4 below $5 \mathrm{~m}$. 


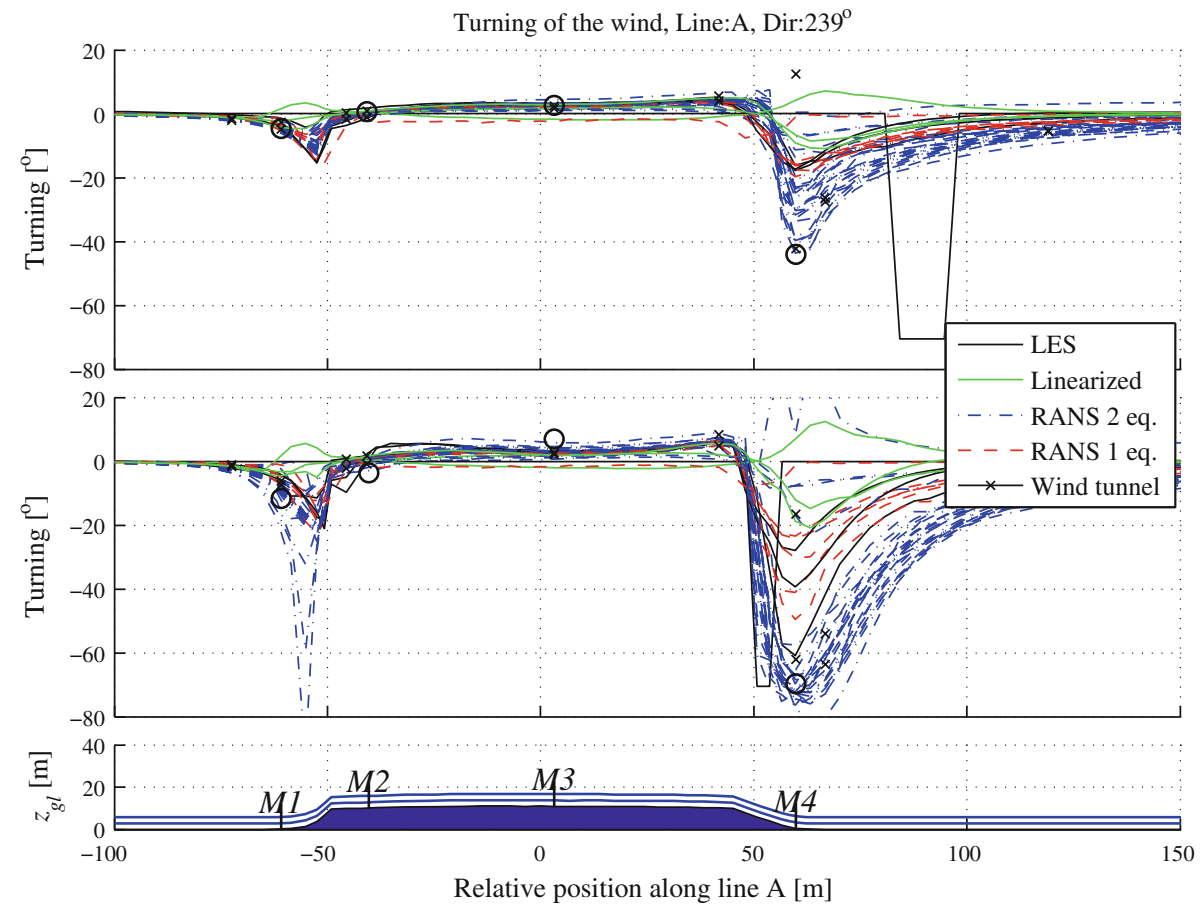

Fig. 7 Turning of the wind along transect A for simulation case 3 as a function of relative position (see Table 1). Top: $z_{\mathrm{agl}}=5 \mathrm{~m}$, bottom: $z_{\mathrm{agl}}=2 \mathrm{~m}$

\subsection{Turbulint Kinetic Energy}

Figures 8, 9 and 10 show the measurements and simulations of the TKE increase for case 3 . Figure 8 shows the TKE increase at $z_{\mathrm{agl}}=2 \mathrm{~m}$ and $z_{\mathrm{agl}}=5 \mathrm{~m}$ along transect $\mathrm{A}$, while Figs. 9 and 10 show the TKE increase profiles at masts M1, M2, M3 and M4. Generally, the largest TKE increases were observed at heights below $5 \mathrm{~m}$, with a particularly high increase at M2. A few RANS models captured the high TKE increase at M2 at $z_{\mathrm{agl}}<5 \mathrm{~m}$ but overestimated at $z_{\mathrm{agl}} \geq 5 \mathrm{~m}$. The steady-state models appeared to inadequately capture the extreme gradient between $2 \mathrm{~m}$ and $5 \mathrm{~m}$. The LES models clearly behaved differently and were able to capture extreme TKE gradients. However, the best performing LES predictions were not as accurate as the best RANS two-equation predictions.

Except for the M4 position, the experimental methods underestimated the TKE increase at all locations. The reason for this result, whether measuring probe limitations or modelling deficiencies, remains to be investigated.

To quantify the error of the simulated TKE, we define the TKE error by

$$
R_{\mathrm{TKE}}=100\left(\frac{\left(I_{\mathrm{s}}-I_{0 \mathrm{~s}}\right)-\left(I_{\mathrm{m}}-I_{0 \mathrm{~m}}\right)}{I_{0 \mathrm{~m}}}\right)
$$

where $I=\sqrt{\bar{k}} / s_{0}$, subscript zero denotes that TKE is taken at the reference location, and subscripts $\mathrm{m}$ and $\mathrm{s}$ denote the measured and simulated values, respectively. The mean absolute TKE error for all simulation cases and for cases 1 and 3 are shown in Table 4. The error for the best performing model within each model type is given in parentheses. Table 4 


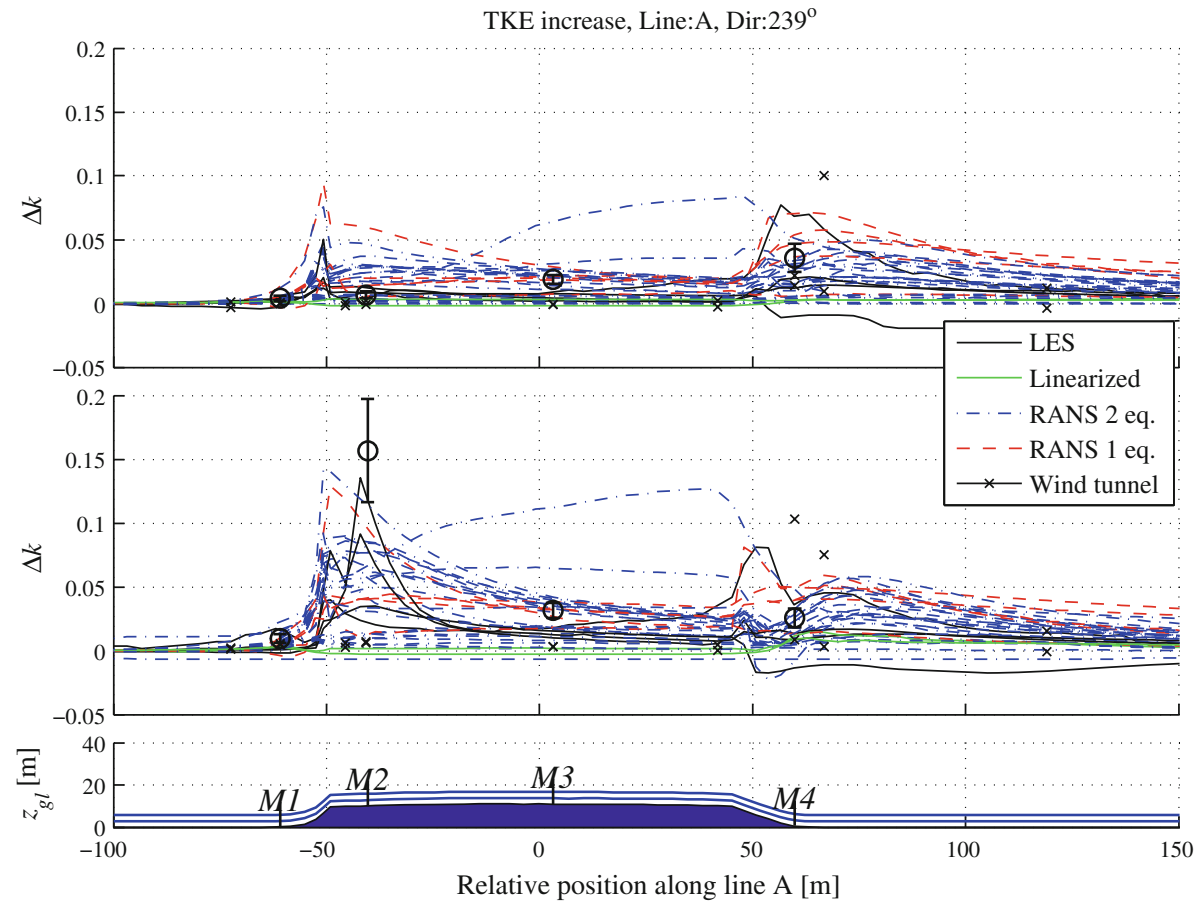

Fig. 8 TKE increase along line A for simulation case 3 as a function of relative position (see Table 1). Top: $z_{\mathrm{agl}}=5 \mathrm{~m}$, bottom: $z_{\mathrm{agl}}=2 \mathrm{~m}$
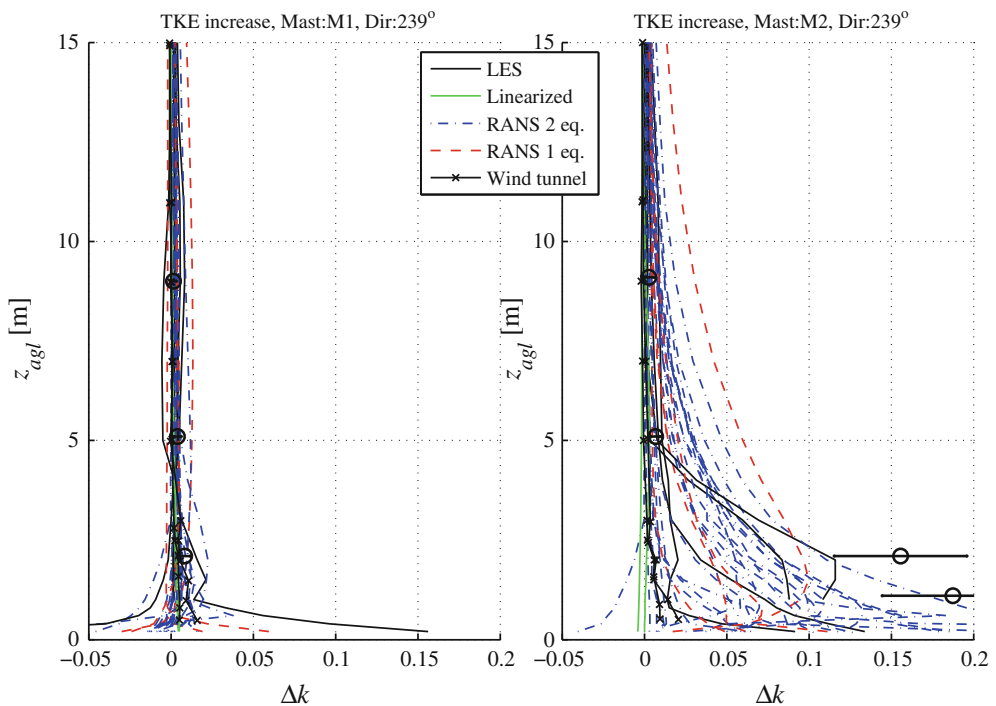

Fig. 9 Left: Simulated and measured TKE increase at M1. Right: TKE increase at M2

shows that the mean error for all models was $49.5 \%$, and that the ranking for model type was $29.9 \%$ for RANS two-equation; $41.6 \%$ for LES; $42.7 \%$ for RANS one-equation; $59.4 \%$ for experimental methods and $71.4 \%$ for linearized models. It is interesting to note that, while the 


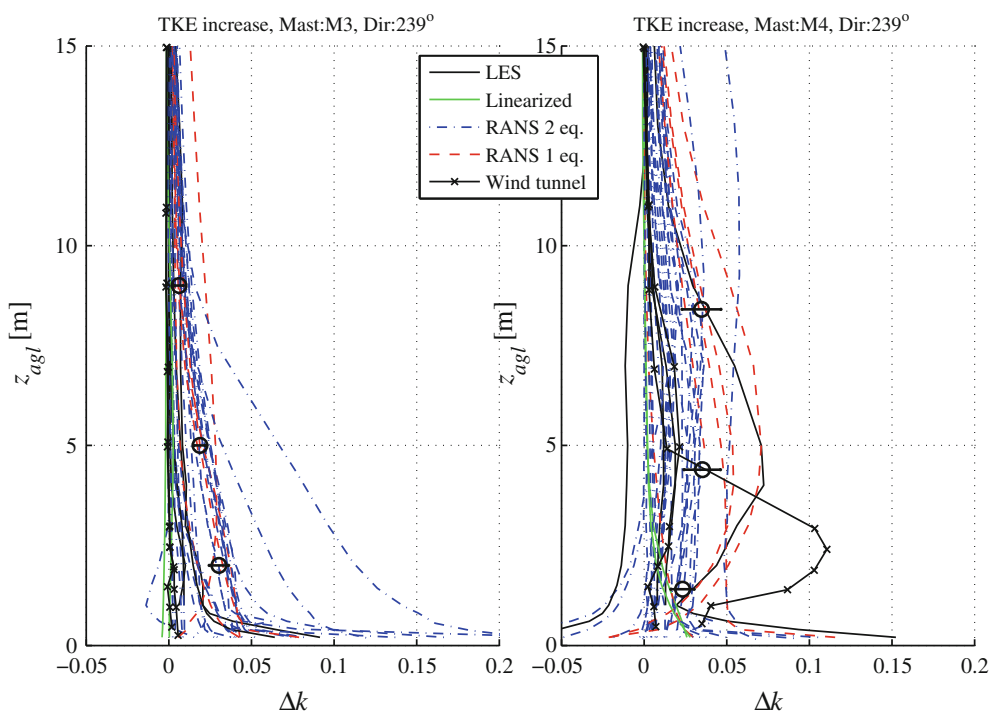

Fig. 10 Left: Simulated and measured TKE increase at M3. Right: TKE increase at M4

Table 4 Mean absolute TKE error (see Eq. 16) for each model type for all sonics for all four simulation cases and case 1 and 3

The numbers in parentheses denote error for the highest performing model of the particular model type

\begin{tabular}{lll}
\hline & All cases & Case 1+3 \\
\hline RANS 2 eq. & $36.9(21.6)$ & $47.0(29.9)$ \\
LES & $35.9(34.6)$ & $48.0(41.6)$ \\
RANS 1 eq. & $36.4(32.4)$ & $44.7(42.7)$ \\
Experiment & - & $61.4(59.4)$ \\
Linearized & $58.8(54.6)$ & $76.7(71.4)$ \\
All models & 38.3 & 49.5 \\
\hline
\end{tabular}

experimental methods performed well in capturing the speed-up, they failed to capture TKE. The opposite occurs for LES, which exhibited large errors on the speed-up but performed slightly better in TKE prediction. It is evident, however, that the RANS two-equation models showed the best performance.

\section{Concluding Remarks}

Based on the Bolund experiment, four simulation cases were defined, and a blind comparison of microscale flow models was performed. All participants were obliged to operate their models to the best of their abilities within a set of specific guidelines and return their results at 600 positions. Because the Bolund wind speed scales solely with friction velocity, it was possible to calculate ensemble-averaged statistics to compare with the predictions. Fifty-seven model predictions were submitted from all branches of the wind-energy industry, showing that the validation of microscale models is a subject of concern for many. Seventyfive percent of the predictions were made using non-linear CFD, which were mostly RANS with the two-equation $k-\varepsilon$ turbulence model. This study clearly indicates that CFD has been 
adopted by the wind industry and that RANS with a two-equation closure must be considered state-of-the-art.

Several LES models participated in the blind comparison; however, only a few results were actually submitted as part of this study. Except for the LES models, all models (including the water channel and wind tunnel) were able to generate the specified free-wind conditions very closely with respect to both wind speed and TKE. This result indicates that it is far from trivial to perform LES over complex terrain, and especially, that free-wind boundary conditions are difficult to control. The Bolund experiment differs from experiments such as the Askervein Hill in that the assumptions of the linearized models are violated through the steepness of the hill and the abrupt roughness change. Considering these factors and the inherently unsteady wind, one would expect the turbulence resolving LES and physical models to show the best results. Apart from the linearized models, however, the LES models showed the largest speed-up errors. LES did show some promise in its ability to capture the extreme near-ground gradients of TKE at M2; however, the results were generally inferior to the steady RANS predictions. The physical models were actually able to quite satisfactorily capture the speed-up. They did, however, significantly underestimate the level of TKE, the reason for which remains to be investigated.

The RANS methods with two-equation turbulence closures generally gave the best results, with the highest performing models showing mean errors for all cases of $\approx 10 \%$ on speed-up and $\approx 22 \%$ on TKE predictions. The errors can, however, hardly be called negligible; they are certainly higher than would be accepted by any wind-farm developer. Perhaps more accurate wind assessments can be achieved if the CFD simulations are based on measurements conducted over complex terrain instead of free-wind measurements. However, because the linearized model errors are twice as large, there is still a clear advantage of using CFD-based methods for complex terrain. The mean speed-up error of the RANS two-equation models was $13.6 \%$, while the best of them had an error of $10.2 \%$. Because the boundary conditions and turbulence closure should be nearly the same for all models, much of this difference is attributed to the numerical approach chosen by the particular modeller. While the scatter is not huge, it still illustrates the importance of having well-trained modellers using wellfounded numerical approaches. This is also underscored by the fact that eight different CFD codes were used to produce the ten best CFD results.

If a simulation tool for resource assessment should be suggested for the wind industry, several considerations must be regarded. Firstly, a method with a well-placed balance between computational efforts and model accuracy is sought. The choice of method should be able to model the governing physical processes in complex terrain while not requiring vast computational efforts. Secondly, apart from some required training efforts, the tool should be directly applicable for the wind industry. While LES and the physical models do provide added information on the turbulent structures of the flow compared to RANS, this advantage must be weighed against the additional simulation time and the complexity in performing the simulations. The wind industry will in any case be reluctant to switch to more sophisticated methods if they have not been verified and validated. Until then, the use of LES for terrain flows will mostly be limited to single-case studies and not used as a standard tool. Solution of the RANS equations with a two-equation closure is more computationally economical, gives good results and has matured from the stage of research tool to a level whereby it can be implemented in the wind industry.

Using the presented measurement and simulation results, microscale modellers can validate their own codes. The smallest mean absolute speed-up error of $10.2 \%$ (case 1-4: 9.6, 10.6, 13.8 and $7.0 \%$ ) was made by ID0017, and the smallest mean absolute TKE error of 
21.6\% (case 1-4: 36.3, 20.3, 23.5 and $6.4 \%$ ) was made by the authors' own contribution, ID0000. Modellers are hereby challenged to improve upon these predictions.

Acknowledgments We would like to thank the Danish Energy Agency (EFP07-Metoder til kortlægning af vindforhold i komplekst terræn (ENS-33033-0062), the Center for Computational Wind Turbine Aerodynamics and Atmospheric Turbulence (under the Danish Council for Strategic Research, Grant No. 09-067216) and Vestas Technology R\&D for financial support. We would also like to thank former Ris $\emptyset$ DTU employee Jeppe Johansen, who envisioned the concept of a field campaign at Bolund and initiated the project together with Hans E. Jørgensen. Without the aid of the technicians in the Test and Measurement section in the wind energy division at Risø DTU, as well as all those Risø DTU employees who helped carrying masts and instruments, this project would not have been possible. Computations were made possible by the use of the Thyra PC-cluster at Risø DTU and DCSC, PC-cluster Yggdrasil. Finally, a special thanks goes to all anonymous contributors who made the blind comparison possible.

Open Access This article is distributed under the terms of the Creative Commons Attribution Noncommercial License which permits any noncommercial use, distribution, and reproduction in any medium, provided the original author(s) and source are credited.

\section{Appendix}

See Appendix Tables A1, A2 and A2.

Table A1 Model details: participant identity (ID), user type (users or model developers) and model type (experimental, CFD or linearized models)

ID User type Model type Turb. model Grid points $\left[\times 10^{6}\right] \quad$ Comp. time [min] CPUs

\begin{tabular}{llllcll}
\hline ID0000 & Developer & CFD model & RANS 2 eq. & 13.0 & 40 & 52 \\
ID0001 & - & Experiment & Water Channel & -- & - & - \\
ID0002 & User & CFD model & RANS 2 eq. & 5.3 & 120 & 8 \\
ID0003 & User & CFD model & LES & 5.3 & 40000 & 8 \\
ID0004 & Developer & CFD model & RANS 2 eq. & 3.5 & - & 3 \\
ID0005 & Developer & CFD model & RANS 2 eq. & 3.5 & - & 3 \\
ID0006 & Developer & CFD model & RANS 2 eq. & 1.0 & - & 4 \\
ID0008 & Developer & Lin. model & No model & 7.4 & 150 & 1 \\
ID0009 & User & CFD model & RANS 2 eq. & 8.2 & 600 & 1 \\
ID0010 & User & CFD model & RANS 2 eq. & 2.5 & 750 & 4 \\
ID0012 & User & CFD model & RANS 2 eq. & 2.5 & 750 & 4 \\
ID0014 & - & Experiment & Wind Tunnel & -- & 960 & 1 \\
ID0015 & User & CFD model & RANS 2 eq. & 1.7 & 500 & 4 \\
ID0016 & User & CFD model & RANS 2 eq. & 3.0 & 1500 & 4 \\
ID0017 & User & CFD model & RANS 2 eq. & 3.9 & 64000 & 1 \\
ID0018 & User & Lin. model & No model & -- & 6 & 1 \\
ID0022 & User & CFD model & RANS 2 eq. & 6.0 & 2015 & 20 \\
ID0023 & User & CFD model & RANS 1 eq. & 4.3 & 45 & 1 \\
ID0024 & User & Lin. model & No model & -- & 0.1 & 1 \\
ID0025 & User & CFD model & RANS 1 eq. & 12.5 & 1219 & 1 \\
ID0026 & User & CFD model & RANS 2 eq. & 2.4 & 1440 & 1 \\
\hline
\end{tabular}


Table A1 Continued

\begin{tabular}{|c|c|c|c|c|c|c|}
\hline ID & User type & Model type & Turb. model & Grid Points $\left[\times 10^{6}\right]$ & Comp. time [min] & CPUs \\
\hline ID0027 & - & - & - & - & - & - \\
\hline ID0031 & User & Lin. model & No model & - & 12 & 1 \\
\hline ID0032 & User & CFD model & RANS 2 eq. & 0.1 & 2880 & 1 \\
\hline ID0033 & User & CFD model & RANS 1 eq. & 1.6 & 96 & 1 \\
\hline ID0034 & User & CFD model & RANS 1 eq. & 2.2 & 360 & 1 \\
\hline ID0036 & Developer & CFD model & RANS 2 eq. & 3.0 & 1200 & 3 \\
\hline ID0037 & Developer & CFD model & RANS 2 eq. & 4.3 & 1440 & 3 \\
\hline ID0041 & Developer & CFD model & LES & 0.1 & 1000 & 1 \\
\hline ID0042 & Developer & CFD model & No model & 0.9 & 7000 & 1 \\
\hline ID0043 & Developer & CFD model & LES & 0.4 & 9000 & 1 \\
\hline ID0045 & Developer & CFD model & RANS 2 eq. & -- & - & - \\
\hline ID0046 & Developer & CFD model & LES & - & - & - \\
\hline ID0047 & User & CFD model & LES & 2.8 & 8640 & 4 \\
\hline ID0053 & Developer & CFD model & RANS 2 eq. & 7.6 & - & 100 \\
\hline ID0055 & User & Lin. model & - & - & 60 & 1 \\
\hline ID0060 & Developer & - & No model & - & 1 & 1 \\
\hline ID0061 & Developer & - & RANS 1 eq. & 0.5 & 50 & 1 \\
\hline ID0062 & Developer & - & - & - & - & - \\
\hline ID0064 & Developer & CFD model & RANS 2 eq. & 11.2 & 4427 & 16 \\
\hline ID0065 & Developer & CFD model & RANS 2 eq. & 11.2 & 5545 & 16 \\
\hline ID0067 & - & CFD model & LES & - & - & - \\
\hline ID0068 & Developer & CFD model & RANS 2 eq. & 1.0 & 6000 & 2 \\
\hline ID0069 & Developer & CFD model & RANS 2 eq. & 1.0 & 6000 & 2 \\
\hline ID0070 & User & CFD model & RANS 1 eq. & 0.7 & 1900 & 1 \\
\hline ID0071 & User & CFD model & RANS 2 eq. & 0.7 & 1900 & 1 \\
\hline ID0077 & User & CFD model & RANS 2 eq. & 1.8 & 200 & 2 \\
\hline ID0078 & User & Lin. model & - & - & 2400 & 1 \\
\hline ID0080 & Developer & CFD model & RANS 2 eq. & 0.5 & 1440 & 1 \\
\hline ID0081 & User & Lin. model & - & 0.6 & 960 & 1 \\
\hline ID0082 & User & CFD model & RANS 1 eq. & 1.5 & 180 & 1 \\
\hline ID0083 & User . & Lin. model & No model & - & 13 & 1 \\
\hline ID0084 & User & CFD model & RANS 2 eq. & 4.8 & 480 & 64 \\
\hline ID0085 & Developer & Lin. model & No model & - & 10 & 1 \\
\hline ID0086 & Developer & Lin. model & RANS 1 eq. & - & - & - \\
\hline ID0087 & Developer & Lin. model & - & - & - & - \\
\hline ID0088 & Developer & CFD model & RANS 2 eq. & - & - & - \\
\hline
\end{tabular}

The table also gives information on the method used. '-' indicates that the question was not answered by the participant. The final three columns give the number of grid points, total computational time (obtained by a wall clock for all cases) and number of CPUs 


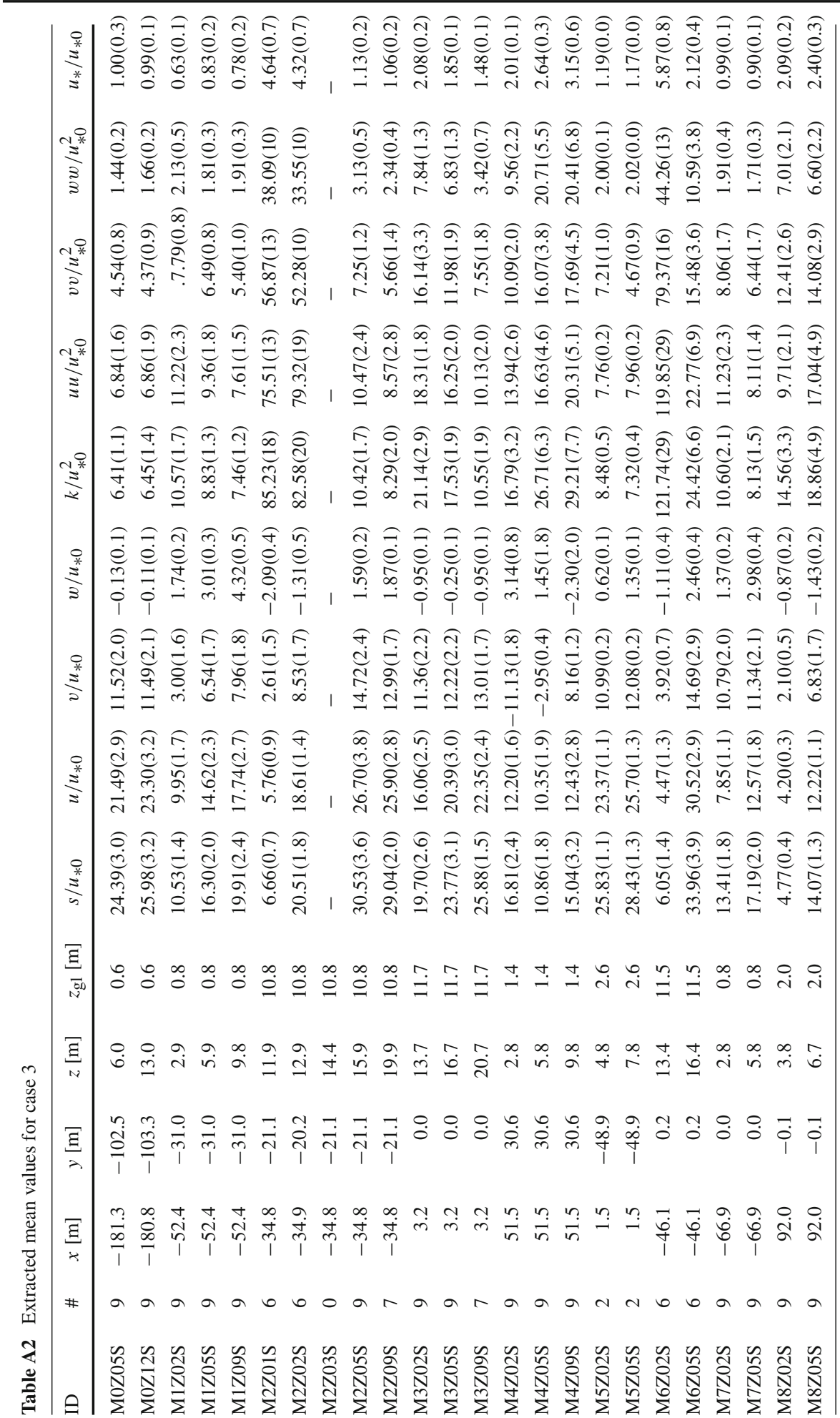




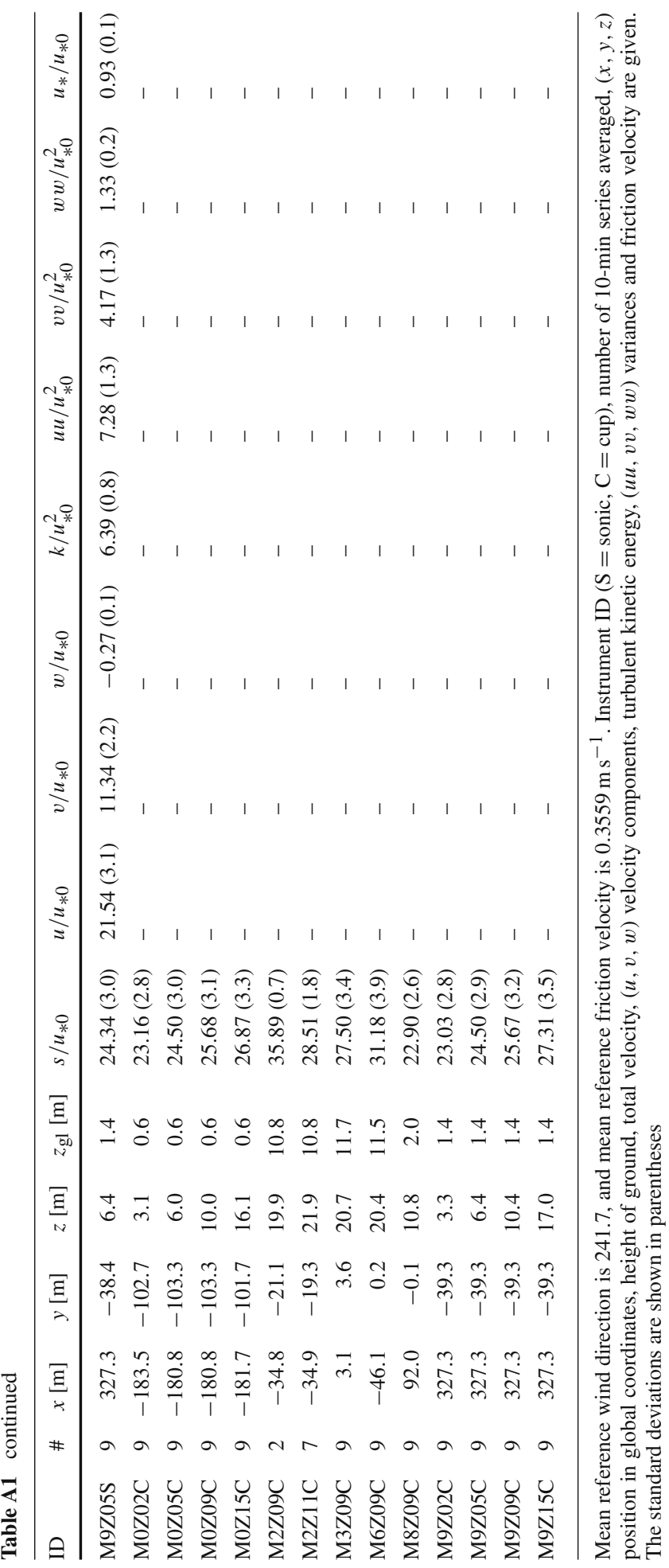




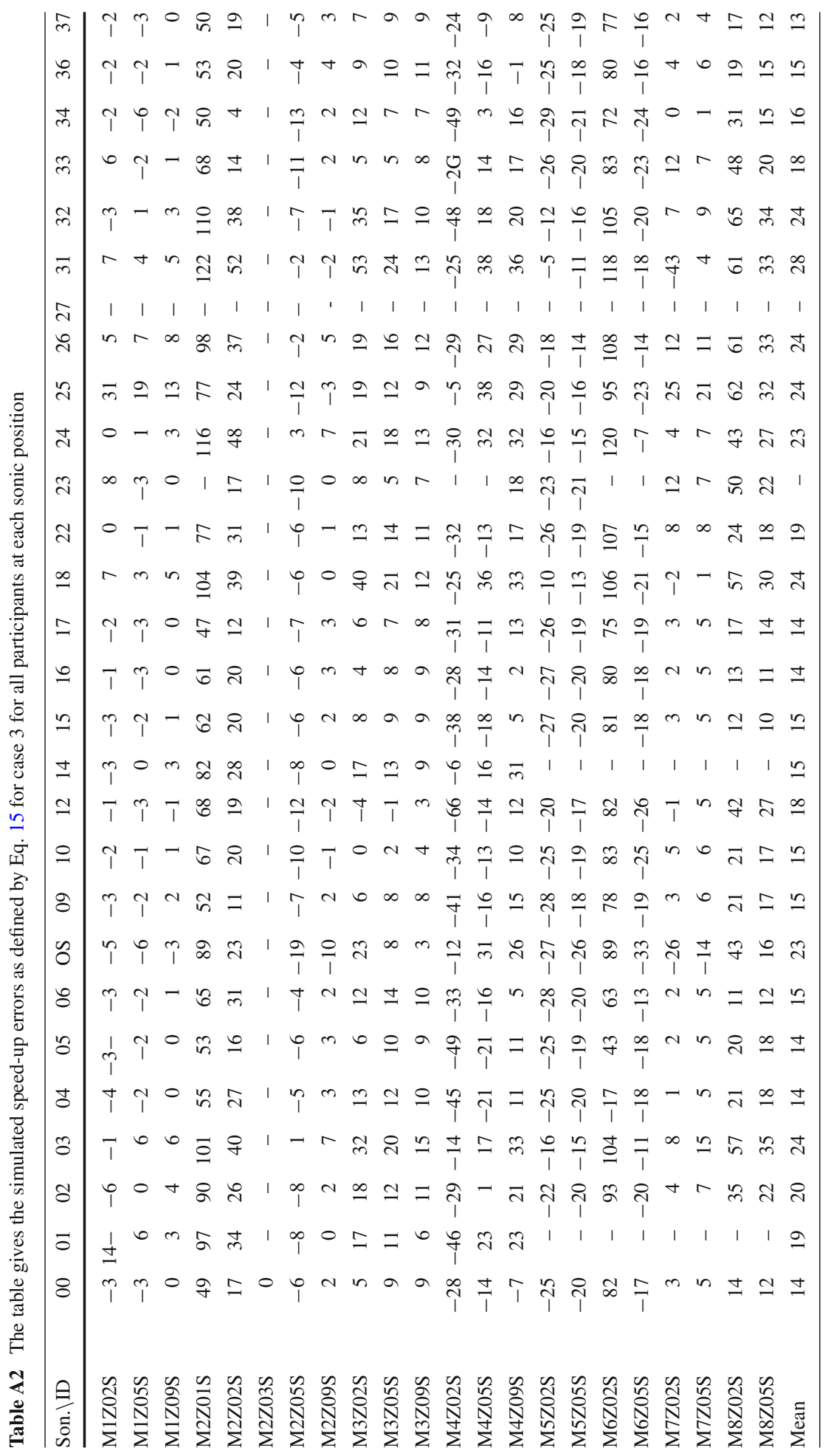




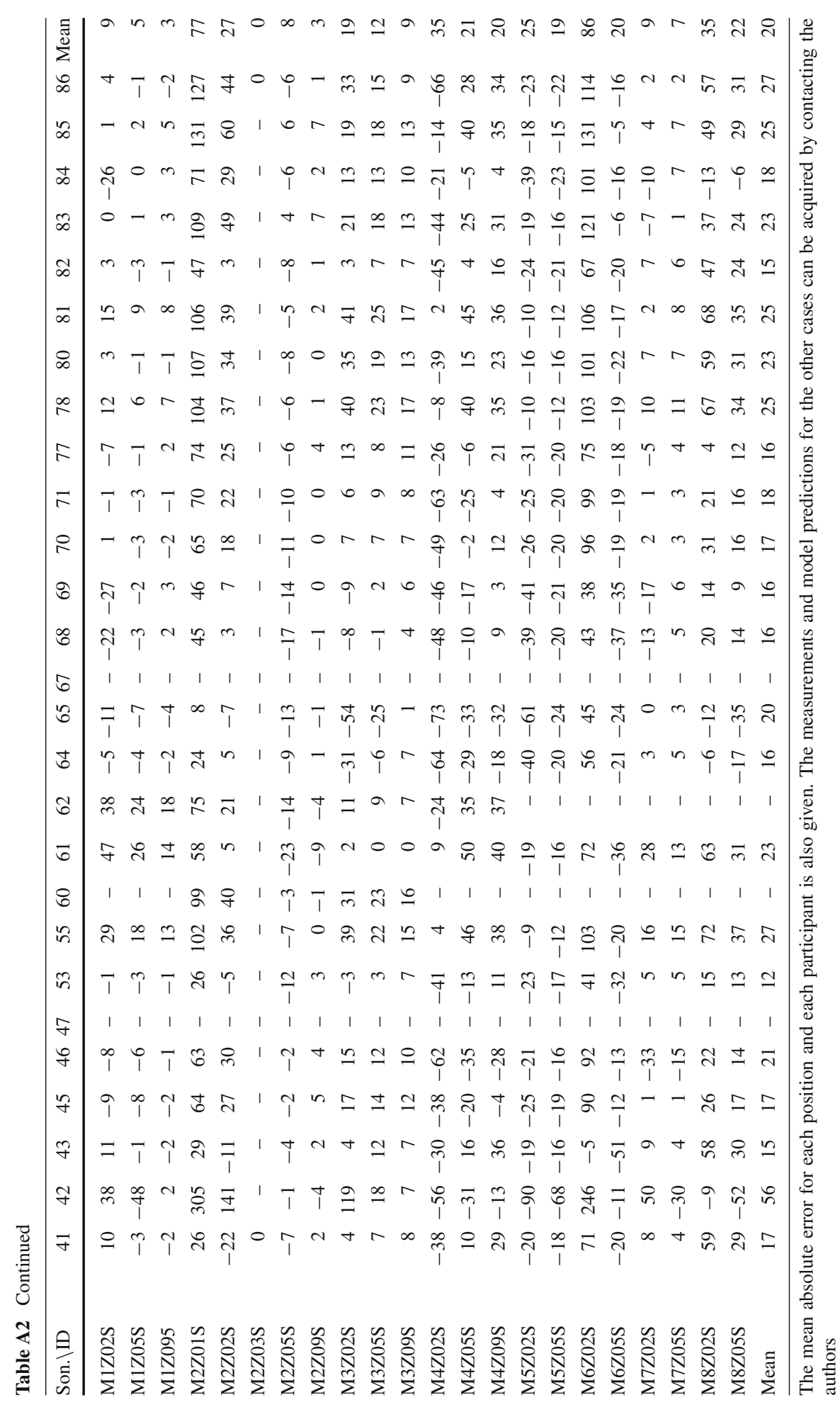




\section{References}

Andren A, Brown A, Graf J, Moeng C, Mason P, Nieuwstadt F, Schumann U (1994) Large-eddy simulation of a neutrally stratified boundary layer: a comparison of four computer codes. Q J Roy Meteorol Soc 120:1457-1484

Apsley D, Castro I (1997) A limited-length-scale $k-\varepsilon$ model for the neutral and stably-stratified atmospheric boundary layer. Boundary-Layer Meteorol 83:75-98

Athanassiadou M, Castro I (2001) Neutral flow over a series of rough hills: a laboratory experiment. Boundary-Layer Meteorol 101:1-30

Bechmann A, Sørensen N (2010a) Hybrid RANS/LES applied to complex terrain. Wind Energy. doi:10.1002/ we. 414

Bechmann A, Sørensen N (2010b) Hybrid RANS/LES method for wind flow over complex terrain. Wind Energy 13:36-50. doi:10.1002/we.246

Bechmann A, Berg J, Courtney M, Jørgensen H, Mann J, Sørensen N (2009) The Bolund experiment: overview and background. Ris $\varnothing$ DTU report Ris $\varnothing-\mathrm{R} 1658(\mathrm{EN}), 50 \mathrm{pp}$

Beljaars A, Walmsley J, Taylor P (1987) A mixed spectral finite difference model for neutrally stratified boundary layer flow over roughness changes and topography. Boundary-Layer Meteorol 38:273-303

Berg J, Mann J, Bechmann A, Courtney M, Jørgensen H (2011) The Bolund experiment, part I: flow over a steep, three-dimensional hill. Boundary-Layer Meteorol (this issue)

Bradley E (1980) An experimental study of the profiles of wind speed, shearing stress and turbulence at the crest of a large hill. Q J Roy Meteorol Soc 106:101-123

Brown A, Hobson J, Wood N (2001) Large-eddy simulation of neutral turbulent flow over rough sinusoidal ridges. Boundary-Layer Meteorol 98:411-441

Castro F, Snyder W (1982) A wind tunnel study of the dispersion from sources downwind of three-dimensional hills. Atmos Environ 16(8):1869-1887

Castro F, Palma J, Silva Lopes A (2003) Simulation of the Askervein flow. part 1: Reynolds averaged NavierStokes equations ( $k-\varepsilon$ turbulence model). Boundary-Layer Meteorol 107:501-530

Chow F, Street R (2009) Evaluation of turbulence closure models for large-eddy simulation over complex terrain: flow over Askervein Hill. J Appl Meteorol 48(5):1050-1065. doi:10.1175/2008JAMC1862.1

Chow F, Weigel A, Street R, Rotach M, Xue M (2006) High-resolution large-eddy simulations of flow in a steep alpine valley. Part I: methodology, verification, and sensitivity experiments. J Appl Meteorol 45(1):63-86

Detering E, Etling E (1985) Application of the $e-\varepsilon$ turbulence model to the atmospheric boundary layer. Boundary-Layer Meteorol 33:113-133

Duynkerke P (1987) Application of the $e-\epsilon$ turbulence closure model to the neutral and stable atmospheric boundary layer. J Atmos Sci 45:865-880

Eidsvik K (2005) AA system for wind power estimation in mountainous terrain. Prediction of Askervein Hill data. Wind Energy 8:237-249

Emeis S, Højstrup M, Jensen N (1993) Hjardemål experiment data report. Ris $\emptyset$ DTU report Ris $\varnothing-M-2289(E N)$, $126 \mathrm{pp}$

Hunt J, Snyder W (1980) Experiments on stable and neutrally stratified flow over a model three-dimensional hill. J Fluid Mech 96(4):671-704

Jackson P, Hunt J (1975) Turbulent wind flow over a low hill. Q J Roy Meteorol Soc 101:929-955

Jenkins G, Mason P, Moores W, Stykes R (1981) Measurements of the flow structure around Ailsa Craig, a steep, three-dimensional, isolated hill. Q J Roy Meteorol Soc 107:833-851

Jensen N, Petersen E, Troen I (1984) Extrapolation of mean wind statistics with special regard to wind energy applications. World Meteorological Organization WCP-86, pp 1-85

Kim H, Patel V (2000) Test of turbulence models for wind flow over terrain with separation and recirculation. Boundary-Layer Meteorol 94:5-21

Launder B, Spalding D (1974) The numerical computation of turbulent flows. Comput Mech Appl Mech Eng 3:269-289

Mason P, King J (1985) Measurements and predictions of flow and turbulence over an isolated hill of moderate slope. Q J Roy Meteorol Soc 111:617-640

Mason P, Stykes R (1979) Flow over an isolated hill of moderate slope. Q J Roy Meteorol Soc 105:383-395

Mason P, Thomson D (1992) Stochastic backscatter in large-eddy simulations of boundary layer. J Fluid Mech 24:51-78

Panofsky H, Dutton J (1984) Atmospheric turbulence models and methods for engineering applications. John Wiley and Sons, New York, $397 \mathrm{pp}$

Porté-Agel F, Meneveau C, Parlange M (2000) A scale-dependent dynamic model for large-eddy simulation: application to a neutral atmospheric boundary layer. J Fluid Mech 415:261-284 
Raithby G, Stubley G, Taylor P (1987) The Askervein Hill project: a finite control volume prediction of three-dimensional flows over the hill. Boundary-Layer Meteorol 39:247-267

Røkenes K, Krogstad PÅ (2009) Wind tunnel simulation of terrain effects on wind farm siting. Wind Energy $12: 391-410$

Salmon R, Teunissen H, Mickle R, Taylor P (1988) The kettles hill project: field observations, wind-tunnel simulations and numerical model predictions for flow over a low hill. Boundary-Layer Meteorol 43:309-342

Silva Lopes A, Palma J, Castro F (2007) Simulation of the Askervein flow. Part 2: large-eddy simulations. Boundary-Layer Meteorol 125:85-108

Simms D, Schreck S, Hand M, Fingersh L (2001) NREL unsteady aerodynamics experiment in the Nasa-Ames wind tunnel: a comparison of predictions to measurements. National Renewable Energy Laboratory NREL/TP-500-29494, $51 \mathrm{pp}$

Sullivan P, McWilliams J, Moeng CH (1994) A subgrid-scale model for large-eddy simulation of planetary boundary layer. Boundary-Layer Meteorol 71:247-276

Taylor PA (1977) Some numerical studies of surface boundary-layer flow above gentle topography. Boundary-Layer Meteorol 11:439-465

Taylor PA, Teunissen H (1987) The Askervein Hill project: overview and background data. Boundary-Layer Meteorol 39:15-39

Taylor PA, Walmsley J, Salmon J (1983) A simple model of neutrally stratified boundary-layer flow over real terrain incorporating wavenumber-dependent scaling. Boundary-Layer Meteorol 26:169-189

Troen I, Petersen E (1989) European wind atlas. Ris $\varnothing$ National Laboratory, Roskilde ISBN: 87-550-1482-8, $656 \mathrm{pp}$

Undheim O, Andersson H, Berge E (2006) Non-linear, microscale modelling of the flow over Askervein Hill. Boundary-Layer Meteorol 120:477-495

Walmsley J, Taylor P (1996) Boundary-layer flow over topography: impacts of the Askervein study. Boundary-Layer Meteorol 78:291-320

Walmsley J, Taylor P, Keith T (1986) A simple model of neutrally stratified boundary-layer flow over complex terrain with surface roughness modulations (ms3djh/3r). Boundary-Layer Meteorol 36:157-186

Walmsley J, Troen I, Lalas D, Mason P (1990) Surface-layer flow in complex terrain: comparison of models and full-scale observations. Boundary-Layer Meteorol 52:259-281

Wan F, Porte-Agel F, Stoll R (2007) Evaluation of dynamic subgrid-scale models in large-eddy simulations of neutral turbulent flow over a two-dimensional sinusoidal hill. Atmos Environ 41(13):2719-2728

Weigel A, Chow F, Rotach M, Street R, Xue M (2006) High-resolution large-eddy simulations of flow in a steep alpine valley. Part II: flow structure and heat budgets. J Appl Meteorol 45(1):87-107

Wood N (1995) The onset of separation in neutral, turbulent flow over hills. Boundary-Layer Meteorol 76:137164

Xu D, Taylor P (1997) An $e-\epsilon-l$ turbulence closure scheme for planetary boundary-layer models: the neutrally stratified case. Boundary-Layer Meteorol 84:247-266

Zeman O, Jensen N (1987) Modification of turbulence characteristics in flow over hills. Q J Roy Meteorol Soc 113:55-80 